\title{
Interdecadal modulation of El Niño-tropical North Atlantic teleconnection by the Atlantic multi-decadal oscillation
}

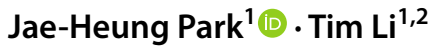 \\ Received: 22 May 2018 / Accepted: 17 September 2018 / Published online: 28 September 2018 \\ (c) The Author(s) 2018
}

\begin{abstract}
It has been well documented that El Niño (La Niña) is able to induce sea surface temperature (SST) warming (cooling) in the tropical North Atlantic (TNA) in the following spring. Based on the observational analysis, in this study we found that such a lagged El Niño-TNA SST relationship is non-stationary and depends on the phase of Atlantic multi-decadal oscillation (AMO). During the AMO negative phase, the influence of El Niño on TNA-SST becomes intensified and lasts longer till the following summer to fall, and vice versa. We demonstrated that such a modulation is through atmospheric teleconnection change because El Niño during the AMO negative phase tends to have a stronger and eastward-shifting SST warming over the eastern Pacific and the SST warming persists longer throughout late spring. It is further shown that both extratropical and tropical teleconnections are important in causing the non-stationary El Niño effect according to the AMO phase. The extratropical teleconnection is through the Pacific-North America pattern, while the tropical teleconnection is via anomalous Walker circulation. The extratropical teleconnection acts primarily during winter to early spring, while the tropical teleconnection appears more important in spring. If AMO remains in its positive phase in the near future, a weak influence of El Niño on TNA-SST is expected to ensue.
\end{abstract}

Keywords El Niño $\cdot$ Tropical North Atlantic (TNA) • Atlantic multi-decadal oscillation (AMO)

\section{Introduction}

It has been shown that sea surface temperature (SST) in the tropical North Atlantic (TNA) plays an important role in climate and weather over its adjacent regions. For instance, numerous studies examined the influence of TNA-SST on surface air temperature, precipitation and atmospheric circulation in the North Atlantic-European regions, the United States, the Caribbean, the northern Brazil, and the western

\section{Tim Li}

timli@hawaii.edu

1 International Pacific Research Center and Department of Atmospheric Sciences, School of Ocean and Earth Science and Technology, University of Hawaii at Manoa, Honolulu, Hawaii, USA

2 Key Laboratory of Meteorological Disaster, Ministry of Education (KLME)/Joint International Research Laboratory of Climate and Environmental Change (ILCEC)/Collaborative Innovation Center on Forecast and Evaluation of Meteorological Disasters (CIC-FEMD), Nanjing University of Information Science and Technology, Nanjing, China
Africa (Folland et al. 1986; Uvo et al. 1998; Chang et al. 2000; Kushnir et al. 2010; Cassou and Terray 2001; Cassou et al. 2004). Furthermore, SST variability in the TNA during boreal summer to fall season exerts an enormous effect on hurricane formation over the Atlantic main developing region (MDR) (Goldenberg et al. 2001; Saunders and Lea 2008; Wang et al. 2008) (for covenience, seasons follow those of the Northern Hemisphere). An important question is thus what causes the SST variability in the TNA.

As one of the primary factors that affect the variability of TNA-SST, North Atlantic oscillation (NAO) has been investigated in great detail (Tourre et al. 1999; Marshall et al. 2001; Okumura et al. 2001; Huang and Shukla 2005). During the NAO positive phase, intensified easterly trade winds associated with strengthened Azores High lead a SST cooling in the TNA via greater latent heat fluxes from the oceanic surface (Giannini et al. 2001).

Another important factor is the El Niño and Southern Oscillation (ENSO). Enfield and Mayer (1997) argued that El Niño could lead a SST warming in the TNA in the spring following El Niño mature winter. A number of studies have been devoted to understand mechanisms behind the observed 
relationship between El Niño and TNA-SST (Klein et al. 1999; Chiang and Sobel 2002; Giannini et al. 2004; Chiang and Lintner 2005; Chang et al. 2006; Lee et al. 2009). Those mechanisms may be grouped into the following two types.

The first type is mid-latitude teleconnection. Pacific-North America (PNA) teleconnection initiated by El Niño heating forms anomalous low sea level pressure (SLP) over the western subtropical Atlantic (Horel and Wallace 1981; Hoskins and Karoly 1981; Wallace and Gutzler 1981; Barnston and Livezey 1987). The low SLP related wind anomaly reduces total wind speed, leading to reduced latent heat fluxes from oceanic surface and thus a warm SST anomaly (SSTA) in the TNA. The second type is tropical teleconnection mechanism. It is primarily through heating induced Kelvin waves that propagate toward Atlantic along the Equator. The Kelvin waves have two effects on the atmospheric circulation over the tropical Atlantic. The first is through induced tropospheric temperature (TT) pattern, which further modifies atmospheric static stability (Chang et al. 2006) and affects local convection. The second is through anomalous Walker circulation. Anomalous downward motion over the tropical Atlantic by the modulated Walker circulation during El Niño weakens Hadley circulation over the Atlantic sector, which modulates the wind speed and latent heat fluxes as well (Wang 2004). The anomalous Walker circulation may cause suppressed convection over Amazon, which may further induce low-level anticyclonic flows straddling the Equator (García-Serrano et al. 2017).

It was noted that not all of El Niño events could cause the TNA-SST warming in the subsequent spring (e.g. Chang 2006). Lee et al. (2008) argued that the duration of El Niño appears crucial. This is because if El Niño dissipates quickly before spring, its teleconnection effect should diminish as well. In addition, one should consider a combination effect of El Niño and NAO because a positive NAO tends to attenuate the effect of El Niño. Thus, understanding the relative role of El Niño and NAO becomes important in the TNASST variability. Giannini et al. (2001) showed that a delayed TNA-SST warming associated with El Nino could be offset by the cooling effect associated to a stronger-than-average NAO, resulting in no significant influence of El Niño on TNA-SST.

Most of previous studies that investigated the relationship between El Niño and TNA-SST focused on the interannual relationship. Figure 1 shows that in the past 160 years such an interannual relationship is quite robust. However, a recent study by Chen et al. (2015) showed the interdecadal change of the interannual relationship among NAO, El Niño and TNA-SST. Motivated by this study, we would like to investigate the observed characteristics of interdecadal modulation of the El Niño-TNA relationship and physical mechanism behind the observed change. In particular, we

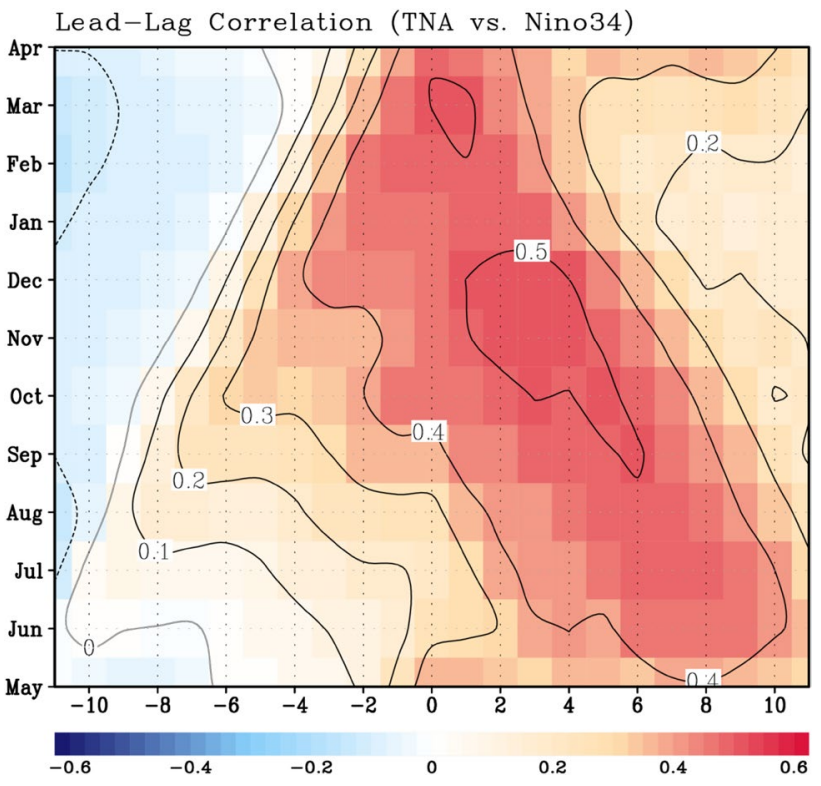

Fig. 1 Monthly lead-lag correlation between tropical North Atlantic $\left(20-100^{\circ} \mathrm{W}, 0-30^{\circ} \mathrm{N}\right)$ and $\mathrm{El}$ Niño represented by Niño3.4 during 1856-2015. In X-axis, negative and positive indicate TNA-lead and El Niño-lead at monthly scale, respectively. Contour interval is 0.1

note that there is a significant interdecadal change of the El Niño-TNA relationship associated with Atlantic multidecadal oscillation (AMO) (Fig. 2). In this study, thus we will focus on examining the interdecadal modulation of the El Niño-TNA relationship based on the AMO phase. The remaining part of this paper is organized as followings. The information about observational datasets used in this study is documented in Sect. 2. From Sect. 3 on, we will present the main results in detail. Summary and discussion will be given in the last section.

\section{Datasets}

NOAA-CIRES twentieth century reanalysis version 2 is adapted because the dataset covers a relatively long period, from 1871 to 2012 (Compo et al. 2011). Thus, it is appropriate to examine the interdecadal modulation of climate phenomena. For the SST analysis, we used Extended Reconstruction Sea Surface Temperature Version 3 (ERSSTv3) (Reynolds et al. 2002), which spans from 1854 to present. It is noted that similar results were obtained when other SST reanalysis datasets such as ERSSTv4 and HadiSST were used.

The way to define the AMO differs according to the methodology used. One way is to extract a pure oscillatory signal of Atlantic-SST by excluding the global warming signal or its trend (Trenberth and Shea 2006; van Oldenborgh et al. 2009). Another way is to define the mean of North Atlantic 
Fig. 2 a 25 year-moving leadlagged correlation coefficients between TNA and El Niño during 1856-2016. In x-axis, negative and positive indicate TNA-lead and El Niño-lead at monthly scale, respectively. Contour interval is 0.15 , and gray hatching indicates the $95 \%$ confidence level by two-tailed t-test. b Red line shows 25 yearmoving correlation coefficients between El Niño and TNA obtained by the average within 3-7 month lag in a. Blue line indicates smoothed AMO index provided by National Ocean and Atmospheric Administration (NOAA) (a) 25yr-Moving lead-lagged Corr. (TNA vs. Nino34)

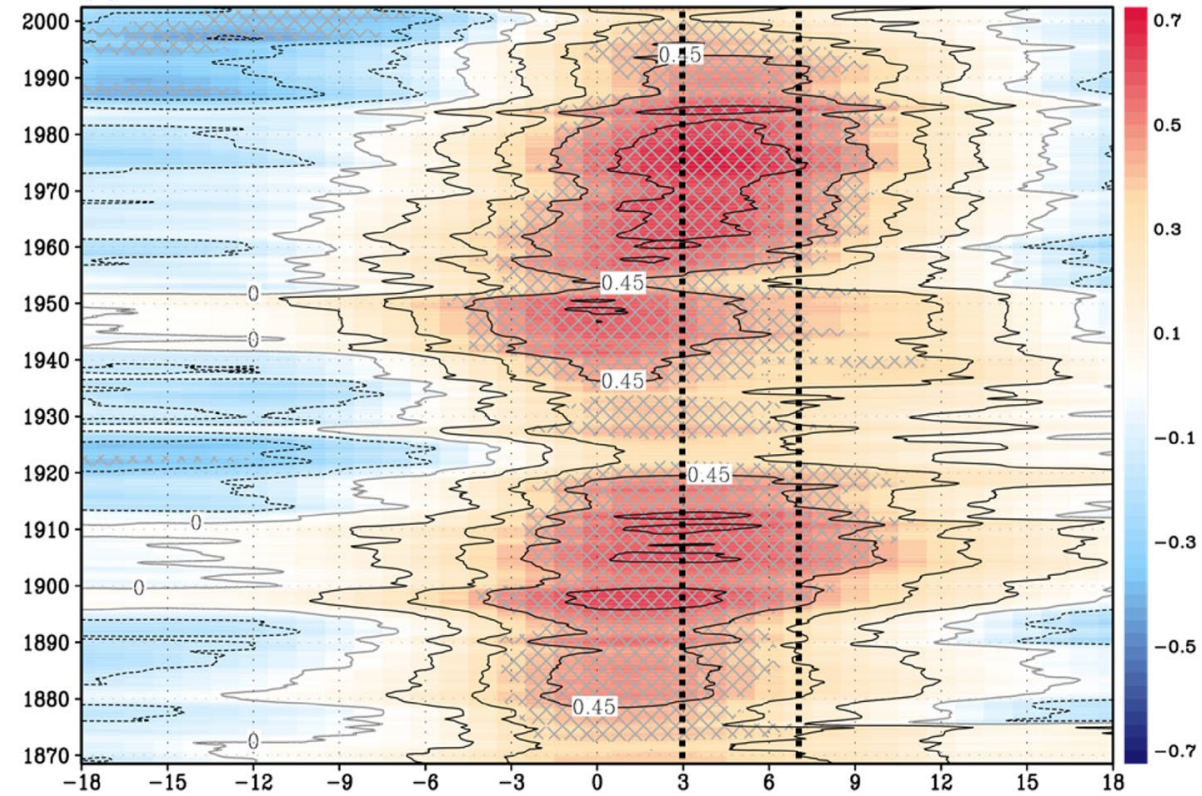

(b) 25yr-Moving Correlation (TNA vs. Nino34) \& AMO

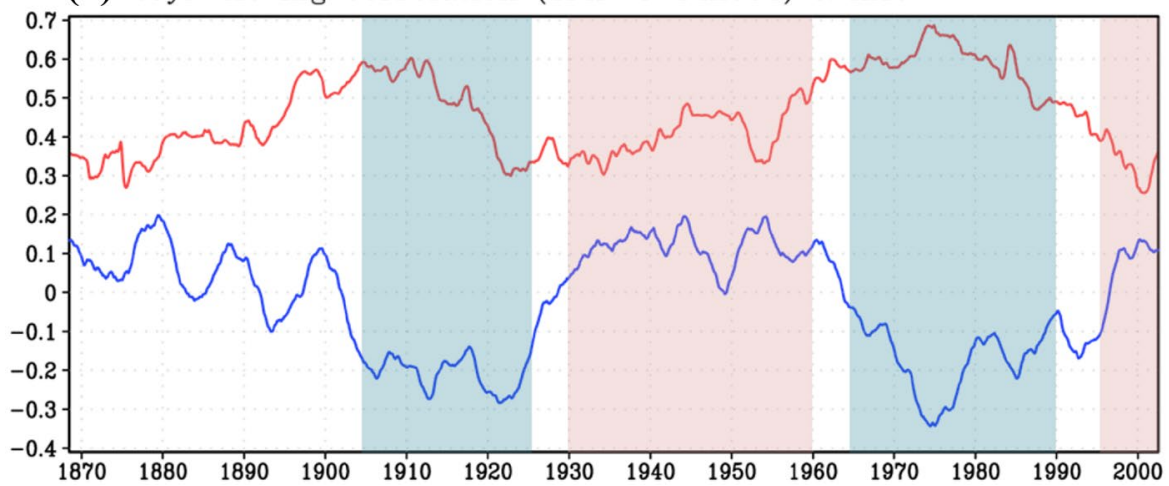

SST after global mean SST trend is removed, following Trenberth and Shea (2006) (Fig. 2b). We believe that the latter is a more objective way to define the AMO index. In this study, we select the latter method and this AMO index can be downloaded from National Oceanic and Atmospheric Administration (NOAA) (refer to https://www.esrl.noaa.gov/ $\mathrm{psd} /$ data/timeseries/AMO/).

In order to examine the influence of El Niño on TNA-SST according to AMO phase, two periods of AMO negative (1905-1925 and 1965-1990, blue shadings) and positive (1930-1960 and 1997-2012, red shadings) phases are composed based on the AMO index, respectively (Fig 2b). As a result, the combination period is 47 years based on the two AMO phase periods. Such a phase composite allows us to understand common features during positive and negative AMO phase. To emphasize the interannual variability of El Niño effect on TNA-SST, trends and the climatological mean in each analysis period were firstly removed.

\section{Non-stationary relationship between EI Niño and TNA}

\subsection{Interdecadal change of the EI Niño-TNA relationship}

To examine overall relationship between El Niño and TNASST, a lead-lagged correlation analysis is conducted using monthly time series. Here, Niño3.4 monthly time series is used as a proxy of El Niño. A TNA-SST index is defined as SST anomalies averaged over $20^{\circ}-100^{\circ} \mathrm{W}$ within $0^{\circ}-30^{\circ} \mathrm{N}$. This area covers most of the tropical to subtropical North Atlantic. In Fig. 1, positive (negative) value in $\mathrm{X}$-axis indicates that El Niño leads (is led by) TNA-SST by x-month, and $y$-axis indicates centered month of the relationship. For example, x-axis: " 6 " and y-axis: "September" mean that Niño3.4 in September leads TNA-SST by 6-month. Maximum correlation is located around $\mathrm{x}$-axis: " 3 " and $\mathrm{y}$-axis: "November". This means that SST in the equatorial Pacific 
in early winter is most influential to TNA-SST in the following spring. The result is consistent with previous studies (e.g. Klein et al. 1999).

Given that there is a decadal change in the relationship between El Niño and TNA-SST (Chen et al. 2015), to examine their non-stationary relationship, we conducted a lead-lagged correlation analysis with 25-year window using monthly time series. Similar to Fig. 1, a positive (negative) value in $\mathrm{X}$-axis means that Niño3.4 leads (is led by) TNASST in Fig. 2a. In the figure, interdecadal modulation of the relationship is verified. The lagged influence of El Niño on TNA-SST was strong around 1900s and 1970s, and weak around 1930s and 2000s, respectively.

To quantify both the intensity and duration of El Niño's effect on TNA-SST, the correlation coefficients within 3-7 lagged month in Fig. 2a are averaged, and the averaged result is illustrated as a red-solid curve in Fig. 2b. Obviously, the interdecadal fluctuation of the El Niño-TNA relationship is clearly seen in the figure. Here, the blue line indicates the smoothed AMO index provided by NOAA. Interestingly, the interdecadal relationship between El Niño and TNA-SST has an opposite tendency to the AMO. In other words, their relationship gets stronger (weaker) during the AMO negative (positive) phase. The result suggests that AMO may greatly modulate the El Niño-TNA relationship.

Besides the AMO, there are several well-known decadal to interdecadal climate modes in the Pacific such as interdecadal Pacific Oscillation (IPO) (Power et al. 1999; Henley et al. 2015), Pacific decadal oscillation (PDO) (Mantua et al. 1997) and Victoria mode (or North Pacific gyre oscillation) (Bond et al. 2003; Di Lorenzo et al. 2008). However, our calculations showed that these climate modes do not have statistically significant correlation with the interdecadal change of the El Niño-TNA relationship (Table 1).

\subsection{AMO phase-dependent EI Niño-TNA relationship}

Using the 47-year merged dataset based on the AMO phases, we conducted a lagged correlation analysis against Niño3.4 index. Here, the Niño3.4 index is defined by as an average of monthly SST anomalies over $120^{\circ}-170^{\circ} \mathrm{W}$ and $5^{\circ} \mathrm{S}-5^{\circ} \mathrm{N}$ in winter $[\mathrm{D}(0) \mathrm{JF}(1)$, where the number denotes order of year]. Figure 3 shows seasonal evolution patterns of SST, SLP, wind, and precipitation anomalies from $\mathrm{D}(0) \mathrm{JF}(1)$ to ASO(1) for both positive and negative AMO phase composites. Note that only those exceeding $95 \%$ confidence levels based on two-tailed t-test are shown in the panels except for SLP. The left and right panels in Fig. 3 present timesequential developments of El Niño's effect during positive and negative phase of AMO, respectively. In $\mathrm{D}(0) \mathrm{JF}(1)$, the influences of El Niño during both AMO phases look similar (Fig. 3a, f), where anomalous negative SLP is seen near
Table 1 The correlation coefficients between the relationship between ENSO-TNA (red line in Fig. 2b) and other primary climate indices, such as AMO, IPO, PDO, NPGO, and NAO

\begin{tabular}{lccccc}
\hline Correl. coeff. (1900-) & AMO & IPO & PDO & NPGO & NAO \\
\hline ENSO-TNA & -0.56 & 0.07 & 0.01 & -0.15 & -0.09 \\
\hline
\end{tabular}

Here, AMO monthly index is obtained from the NOAA (blue line in Fig. 2b). IPO is defined through an areal-average of monthly SST anomaly over the three regions (region $1: 140^{\circ} \mathrm{E}-145^{\circ} \mathrm{W}, 25^{\circ}-$ $45^{\circ} \mathrm{N}$, region 2: $170^{\circ} \mathrm{E}-90^{\circ} \mathrm{W}, 10^{\circ} \mathrm{S}-10^{\circ} \mathrm{N}$, region $3: 150^{\circ} \mathrm{E}-140^{\circ} \mathrm{W}$, $15^{\circ}-50^{\circ} \mathrm{S}$, region $2-$ [region $1+$ region 3)/2] (Henley et al. 2015). For PDO and NPGO, EOF analysis are conducted with monthly SST anomalies over the North Pacific $\left(120^{\circ} \mathrm{E}-120^{\circ} \mathrm{W}, 20^{\circ}-70^{\circ} \mathrm{N}\right)$, and their PC time series are used to get their indices (Mantua et al. 1997; Bond et al. 2003). Here, PDO is associated with a horseshoe SST pattern, where the pattern with negative SST anomaly over the North Pacific is taken as its positive phase. NPGO is associated with a meridional tripole pattern, where a positive-negative-positive SST pattern from north to south is taken as its positive phase. For NAO, monthly areal-averaged SLPA (region $1: 10^{\circ}-40^{\circ} \mathrm{W}, 30^{\circ}-$ $40^{\circ} \mathrm{N}$, region $2: 20^{\circ}-50^{\circ} \mathrm{W}, 55^{\circ}-65^{\circ} \mathrm{N}$ ) is used (Hurrell et al. 2013). The averaged SLPA monthly time series in each region is normalized and their difference (region 1 - region 2) is defined as a NAO index. Analysis here is on the basis of 1900-2016 (for the NAO 1900-2012), and all of indices are 5-year-moving averaged to remove interannual signals

the eastern region of Florida peninsula. This corresponds to the last action center of the PNA wave train pattern (Wallace and Gutzler 1981). Over the tropical Atlantic, there exists anomalous high pressure and negative precipitation anomaly, probably associated with sinking branch of anomalous Walker circulation induced by El Niño. Between the tropical high SLP and the subtropical low SLP anomalies (weakening of the meridional SLP gradient) lie anomalous southwesterlies, which contribute to the TNA-SST warming via reduced surface latent heat fluxes as it interacts with the northeasterly mean trade (Klein et al. 1999).

However, after FMA(1) quite different developments of the El Niño effect on the Atlantic are seen for positive and negative AMO phases. During the AMO positive phase, the overall features of El Niño effect on the TNA in $\mathrm{D}(0) \mathrm{JF}(1)$ seem to persist until FMA(1) (Fig. 3b). Over the AMJ(1) to ASO(1) (Fig. 3c-e), the El Niño effect quickly decays. As a result, significant influence over the TNA is not seen after ASO(1).

On the contrary, during the AMO negative phase there is a more pronounced El Niño effect on the Atlantic in FMA(1) (Fig. 3g). In this season, the negative SLP anomaly (SLPA) near the Florida peninsular moves and expands eastward to the central North Atlantic, which is associated with strong anomalous southwesterly winds over the entire TNA. Accordingly, SST in the entire TNA gets warmer. Meanwhile significant easterly wind anomalies appeared along the equatorial Atlantic. 
Correlation (vs. Nino34:D0JF1, AMO:Pos. \& AMo:Neg. )

(a) $\mathrm{D}(0) \mathrm{JF}(1)$

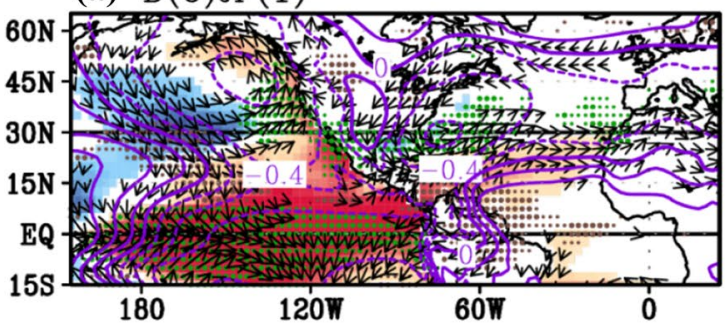

(b) FMA(1)

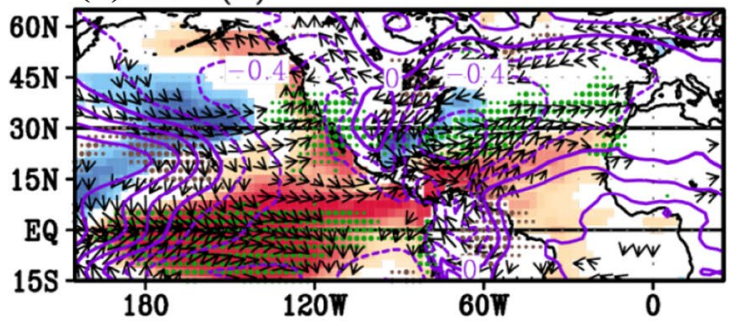

(c) $\operatorname{AMJ}(1)$

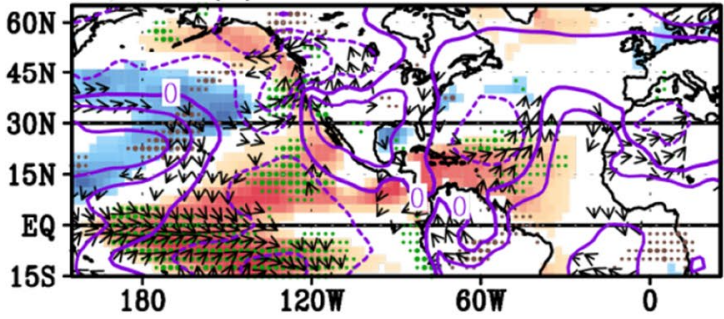

(d) $\mathrm{JJA}(1)$

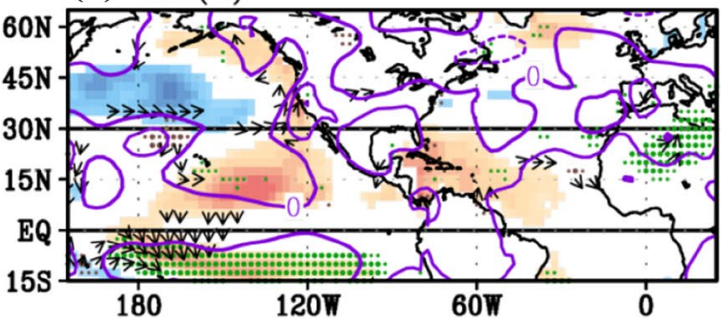

(e) $\mathrm{ASO}(1)$

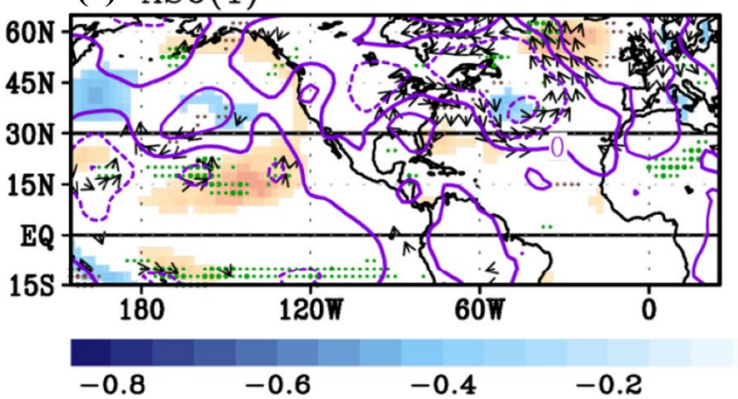

Fig. 3 Lagged correlation maps of SST (shaded only above 95\% confidence level, shading bar is located at bottom), SLP (contour, contour interval is 0.2 ), precipitation (green and brown dots for positive and negative, marked only beyond $95 \%$ confident level), and wind (grey (f) $\mathrm{D}(0) \mathrm{JF}(1)$

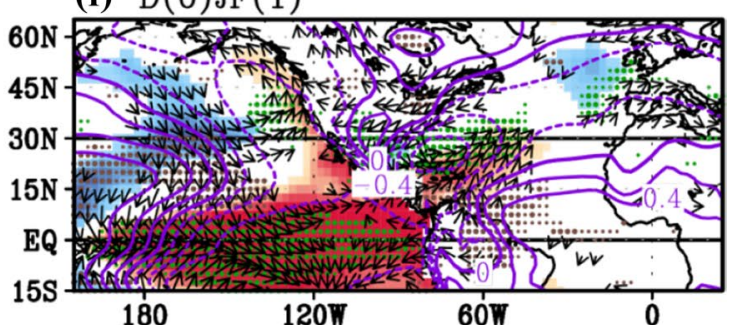

(g) FMA(1)

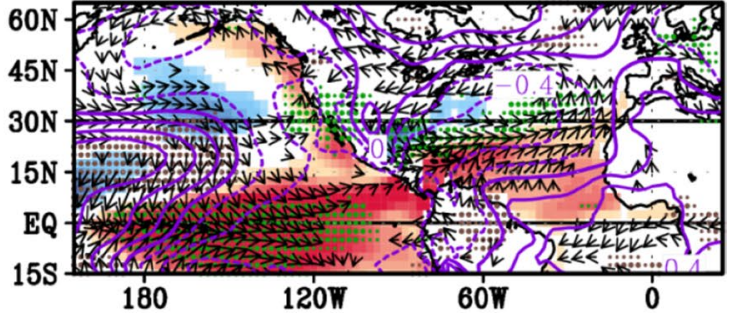

(h) $\operatorname{AMJ}(1)$

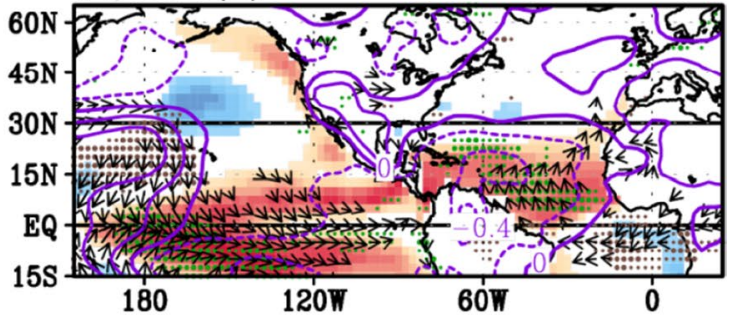

(i) $\mathrm{JJA}(1)$

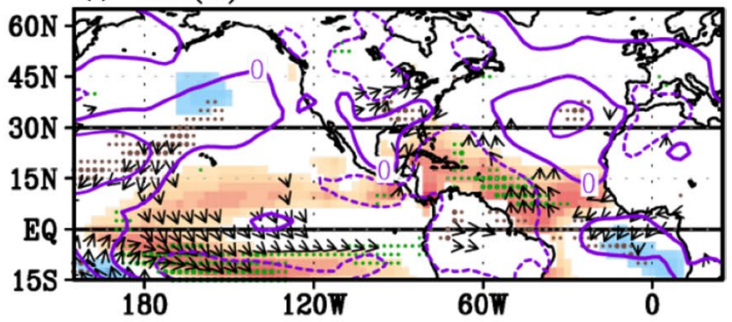

(j) $\mathrm{ASO}(1)$

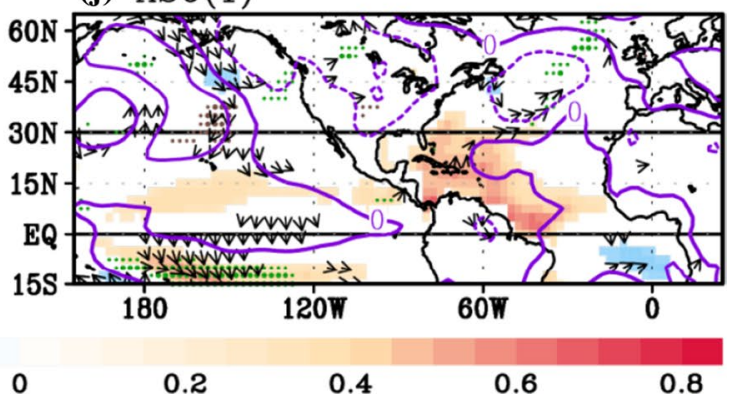

vectors, marked only above $95 \%$ confident level) anomalies against Niño3.4 index (D0JF1). a-e Correspond to $\mathrm{D}(0) \mathrm{JF}(1)$, FMA(1), $\operatorname{AMJ}(1), \operatorname{JJA}(1)$, and $\operatorname{ASO}(1)$ for the positive AMO phase and $\mathbf{f}-\mathbf{j}$ are same to $\mathbf{a}-\mathbf{e}$ but for the negative AMO phase 
In AMJ(1) (Fig. 3h), the easterly wind anomalies over the equatorial Atlantic are further organized and connected to southerly/southwesterly wind anomalies over the subtropics. Together they form anomalous anticyclonic circulation over the eastern subtropical Atlantic. With the anomalous wind forcing, TNA-SST warming persists. In JJA(1) (Fig. 3i), the anomalous easterly wind along the Equator, southerly/southwesterly wind over the TNA and associated anticyclonic circulation are still clearly seen even though its intensity is reduced. As a result, significant SST warming is still presented in large areas over the TNA until ASO(1) (Fig. 3j). Meanwhile, a SST cooling appears over the equatorial region where the easterly wind anomaly is pronounced, which will be briefly discussed later. Note that, the similar result to the Fig. 3 can be obtained for individual AMO phases.

\section{Cause of the non-stationary relationship between El Niño and TNA}

\subsection{Surface heat flux in the TNA}

To understand what contributes to the non-stationary relationship, the difference of total surface heat fluxes including radiative short and longwave, latent heat, and sensible heat are examined. This analysis helps us to reveal the main contributors for distinctive SST warming over the Atlantic between positive and negative AMO phases. Figure 4 describes the regressed total surface heat fluxes (contour) and latent heat fluxes (shading) only against Niño3.4 index because the total surface heat flux is dominated by latent heat flux. In the figure, plus (minus) sign means upward

Regression (Total-SHF \& LH vs. Nino3.4)
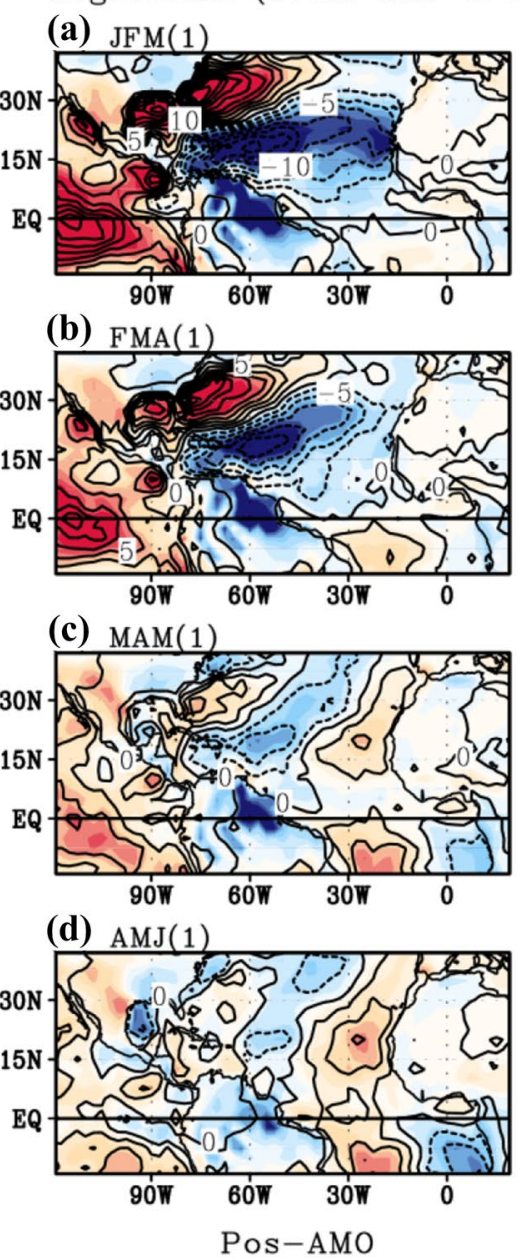

(e) $\operatorname{JFM}(1)$
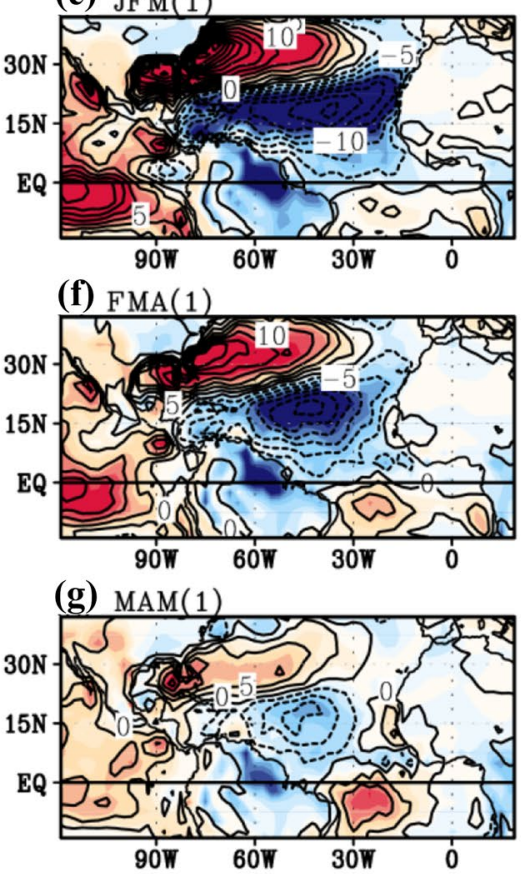

(h) $\operatorname{AMJ}(1)$

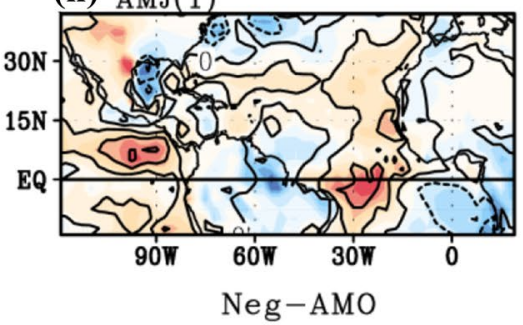

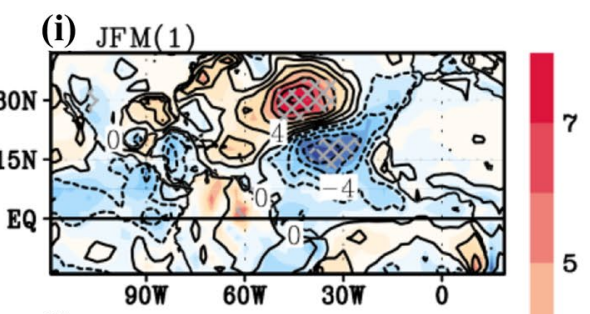

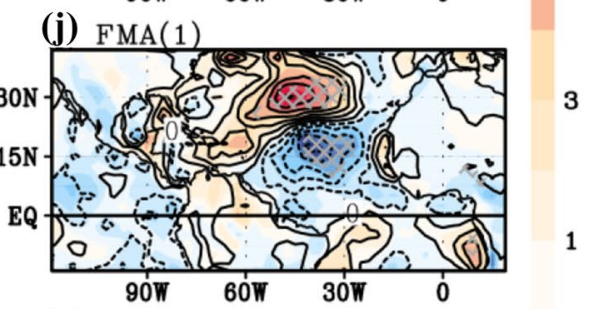

(k) $\operatorname{MAM}(1)$

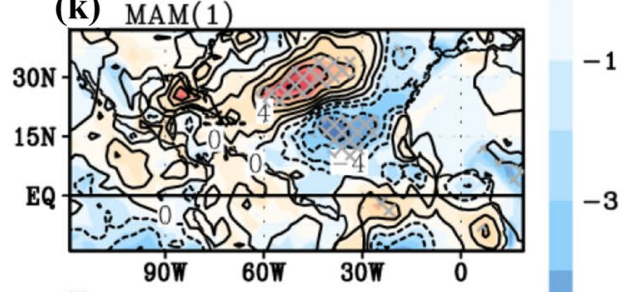

(l) $\operatorname{AMJ}(1)$

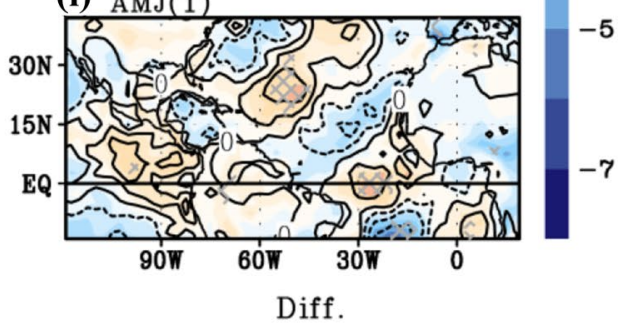

Fig. 4 Lagged regression maps of total surface heat flux (contour, intervals are $2.5 \mathrm{~W} / \mathrm{M}^{2}$ ) and latent heat flux (shading, W/ $\mathrm{M}^{2}$, shading bar is on the right) with respect to Nino3.4 index [D(0)JF(1)] in a $\operatorname{JFM}(1)$, b FMA(1), c MAM(1), and d AMJ(1) during the AMO posi- tive phase; $\mathbf{e}-\mathbf{h}$ are same as $\mathbf{a}-\mathbf{d}$ but during AMO negative phase; $\mathbf{i}-\mathbf{l}$ indicate their differences between two AMO phases (negative-positive), where gray hatching shows $90 \%$ confidence level in latent heat flux by bootstrap method 
(downward) direction of surface heat fluxes from oceanic surface.

During the AMO positive phase (left column in Fig. 4), negative total surface heat fluxes primarily appear over the most part of TNA except near the southeastern United States until spring. On the contrary, during negative phase of AMO (second column in Fig. 4), a negative surface heat flux anomaly over the TNA is stronger and expanded eastward. Consequently, compared to the AMO positive phase, intensified negative surface heat fluxes are found more over the TNA during the AMO negative phase (third column in Fig. 4). This result means prominent SST warming in the TNA during AMO negative phase.

The difference in the surface latent heat fluxes are primarily attributed to the difference in surface wind speed. Climatologically, northeasterly trade wind dominates over the TNA throughout the year. It is noted that the decrease of the surface latent heat flux is due to anomalous southwesterly wind over the region, as seen from the anomalous wind fields shown in Fig. 3.

The result above indicates that the prolonged warming during AMO negative phase is attributed to the maintenance of wind induced surface latent heat flux anomalies over the TNA. Therefore, the key issue related to the enhanced El Niño effect on TNA-SST during negative phase of AMO is what induces stronger anomalous southeasterly wind over the TNA.

\subsection{Lower level atmospheric circulation}

To examine how El Niño influences lower-level atmospheric circulation, we conducted a lagged regression analysis against the Niño3.4 index for positive and negative AMO phases. In the first and the second columns in Fig. 5,

Regression (SLP \& Wind vs. Nino3.4)

(a) $\mathrm{JFM}(1)$

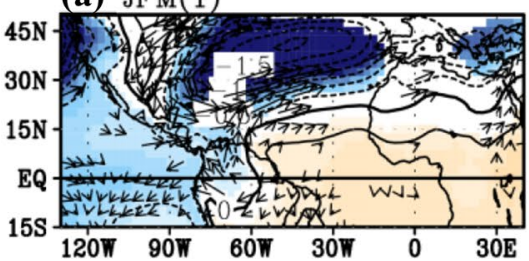

(b) FMA(1)

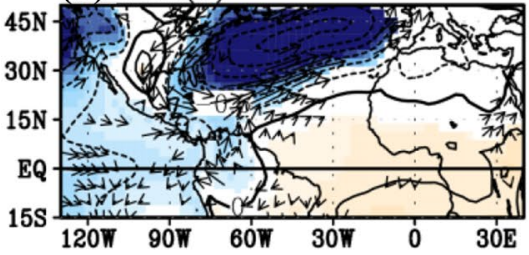

(c) $\operatorname{MAM}(1)$

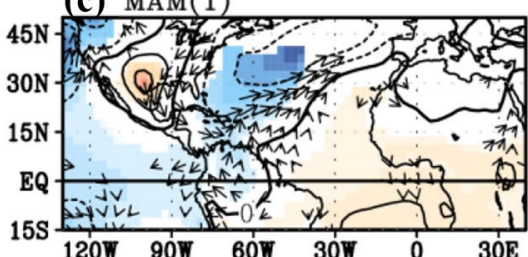

(d) $\operatorname{AMJ}(1)$

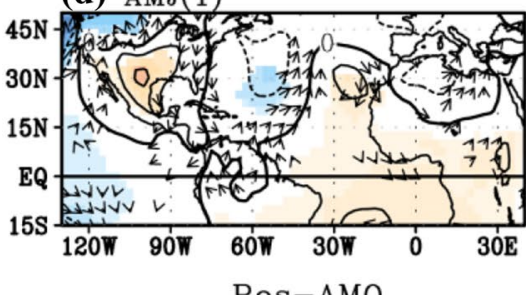

Pos-AMO

\section{(e) $\operatorname{JFM}(1)$}

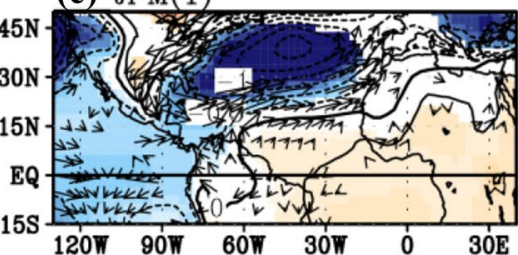

(f) $\mathrm{FMA}(1)$

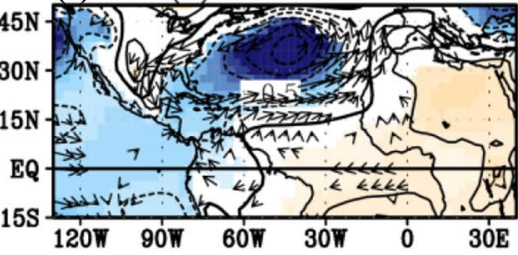

(g) $\operatorname{MAM}(1)$

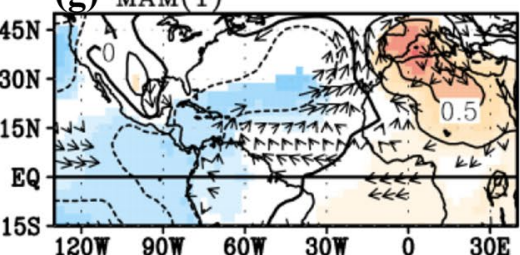

(h) $\operatorname{AMJ}(1)$

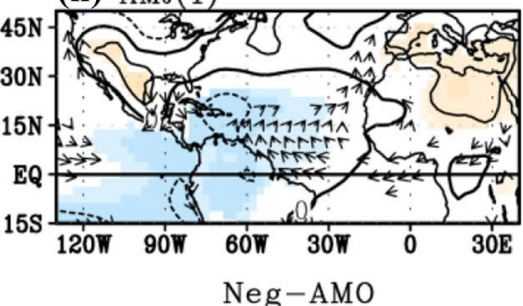

(i) $\mathrm{JFM}(1)$

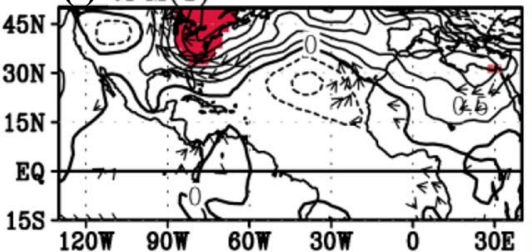

(j) FMA(1)

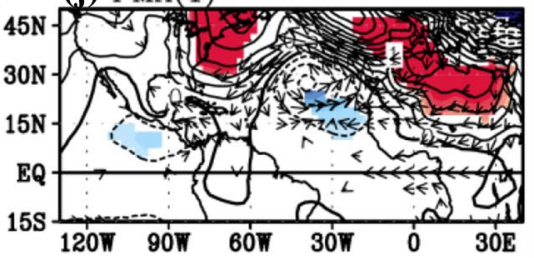

0.5

0.3

0.1

(k) $\operatorname{MAM}(1)$

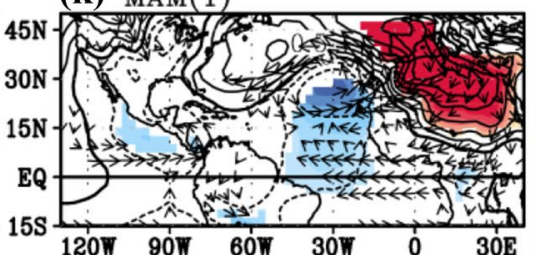

(l) $\operatorname{AMJ}(1)$

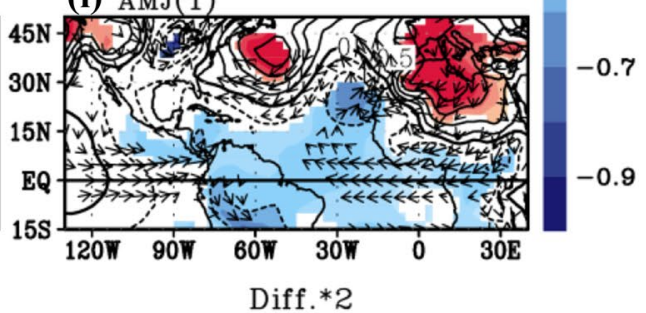

Fig. 5 SLP (contour, interval $0.25 \mathrm{hPa}$ ) and $850 \mathrm{hPa}$ wind (vector) anomalies regressed onto Nino3.4 index [D(0)JF(1)] during the AMO positive phase in a JFM(1), b FMA(1), c MAM(1), and d $\operatorname{AMJ}(1)$, respectively. Above $90 \%$ confidence level by two-tailed t-test is shaded for SLPA and marked for wind anomalies; $\mathbf{e}-\mathbf{h}$ are same as a-d, but during AMO negative phase; $\mathbf{i}-\mathbf{l}$ depict differences between both AMO phases (negative-positive), where shading and vectors indicates the SLP and wind anomalies at $90 \%$ confidence level by bootstrap method 
regressed SLPA and low-level wind anomalies are shown during positive and negative AMO phases, respectively. Third column depicts difference of SLPA and low-level wind anomalies between both AMO phases (negative-positive).

In JFM(1), strong negative SLPA locates over the midlatitude in the Atlantic during both AMO phases. Such a negative SLPA accompanies anomalous cyclonic circulation with pronounced anomalous southwesterly wind over the TNA. Interacting with the mean northeasterly trade winds, the southwesterly wind anomaly acts to reduce total wind speed, leading to less latent heat flux from oceanic surface (Fig. 4). In turn, the positive SSTA forms over the TNA. The negative SLPA maintains in FMA(1). However, the negative SLPA and southwesterly wind anomalies are displaced more eastward in the TNA during AMO negative phase (Fig. 5j), which means that intensified SST warming forms over there. In MAM(1), the anomalous negative SLP and cyclonic circulation persist during AMO negative phase (Fig. 5k). At this moment, easterly wind anomalies along the equatorial Atlantic are connected to the southwesterly wind anomaly over the TNA. Consequently, an anomalous anticyclonic circulation is located over the eastern Atlantic. In AMJ(1), the same circulation pattern can still be seen.

That difference of surface wind anomaly over the TNA between the positive and negative AMO phases is likely attributed to the difference in El Niño forcing and associated teleconnection patterns. In the subsequent subsections, we will examine the differences of El Niño in intensity, evolution, and atmospheric teleconnection between the positive and negative AMO phases.

\subsection{El Niño characteristics according to the AMO phase}

El Niño is known to be able to effect on climate variability of the Atlantic through extratropical and tropical teleconnections. The former is represented by PNA-like wave train pattern. The latter is represented by anomalous Walker Circulation. Thus, it is necessary to investigate both the teleconnections during each AMO phase in detail. Before examining the teleconnections, we first examine how El Niño characteristics change according to both phases of AMO. This is because different tropical SST patterns and intensities may generate different extratropical or tropical teleconnections. It helps us to understand why atmospheric teleconnections differ under the different AMO phases.

In Fig. 6a, contour indicates the regression pattern of SSTA against Niño3.4 index during the AMO positive phase. In $\mathrm{D}(0) \mathrm{JF}(1)$, high regression coefficient is seen over the $120^{\circ}-160^{\circ} \mathrm{W}$. As time goes by, the amplitude gets decreased as its center shifts somewhat to the west. Meanwhile, shading depicts differences in regressed SSTA patterns between both AMO phases (negative-positive). It is known that
SSTA gets larger (smaller) over the eastern (western) Pacific during the AMO negative phase, compared to the AMO positive phase. To put it another way, SST warming is strengthened and maximum center shifts eastward during the AMO negative phase. Such SST warming in the eastern Pacific is greatest from FMA(1) to $\mathrm{AMJ}(1)$. Thus, SST warming in the eastern Pacific is maintained till late spring during the AMO negative phase (Fig. 6b-e). Accompanied by the SSTA evolution pattern is significantly enhanced precipitation anomaly over the off-equatorial eastern North Pacific where the mean Pacific ITCZ locates. It is expected that such a precipitation pattern would strengthen atmospheric teleconnection patterns over tropical Atlantic, which will be discussed in the subsequent subsection.

\subsection{Atmospheric teleconnections}

\subsubsection{Extratropical teleconnection}

First, we investigate how extratropical teleconnection can be modulated according to the different El Niño characteristics. Figure $7 \mathrm{a}$, d show regression patterns of anomalous geopotential height (GPH) at $500 \mathrm{hPa}$ (shading) and anomalous horizontal winds (contour) against Niño3.4 index during AMO positive (left) and negative (right) phases, where only those above $95 \%$ confidence level are shown. A PNAlike wave train pattern is clearly seen in both phases, with a negative GPH anomaly center located near the southeastern region of the United States. Note that the GPH pattern is somewhat different from a typical PNA pattern since these wave train patterns correspond to the FMA(1), not $\mathrm{D}(0) \mathrm{JF}(1)$. Over the southern edge of the GPH anomaly center, southwesterly wind anomalies are pronounced. It is noticed that the southwesterly winds are stronger and spread more over the TNA during the AMO negative phase, which explains the intensified effect of El Niño on TNA-SST warming.

Since El Niño simultaneously generates atmospheric teleconnections through the Tropics and the extratropics, we intend to investigate separately their roles. A specific question to be addressed is which teleconnection component is more important in the generation of southwesterly wind anomaly over the TNA in FMA(1). To address the question, we separated the Nino3.4 index into two parts (An and Wang 2005), where one is related to tropical-teleconnection part and the other is related to extratropical-teleconnection part.

$X(t)=X^{*}(t)-Y(t) \times \frac{\operatorname{COV}\left(X^{*}, Y\right)}{\operatorname{Var}(Y)}$

For the separation [refer to the Eq. (1)], we first define an extratropical teleconnection index $[Y(t)]$, based on the GPH amplitude in teleconnection centers, similar to the definition 
Fig. 6 a Hovmoler diagram of regressed equatorial SSTA $\left(5^{\circ} \mathrm{S}-5^{\circ} \mathrm{N}\right)$ against Niño3.4 index $[\mathrm{D}(0) \mathrm{JF}(1)]$ from $\mathrm{D}(0)$ $\mathrm{JF}(1)$ to JJA(1). Herein, contour (interval, 0.1) indicates the coefficients for AMO positive phase, and shading shows coefficient differences between both AMO phases (negative-positive); $\mathbf{b}$ is similar to $\mathbf{a}$, but shows a regression map. Contour (interval, 0.25 ) indicates regression coefficients of SSTA during an AMO positive phase, and shading shows coefficient differences between both AMO phases (negative-positive, above 90\% confidence level by bootstrap method is hatched). In this figure, coefficient differences of anomalous precipitation are also illustrated by dots (brown and green for negative and positive, above $90 \%$ confidence level by bootstrap method is marked); c-e are same as $\mathbf{a}$, but with different season for FMA(1), $\operatorname{MAM}(1)$, and $\operatorname{AMJ}(1)$, respectively
Regr. (SSTa vs. Nino34:D0JF1)

(a) Ave. $(5 \mathrm{~S}-5 \mathrm{~N})$

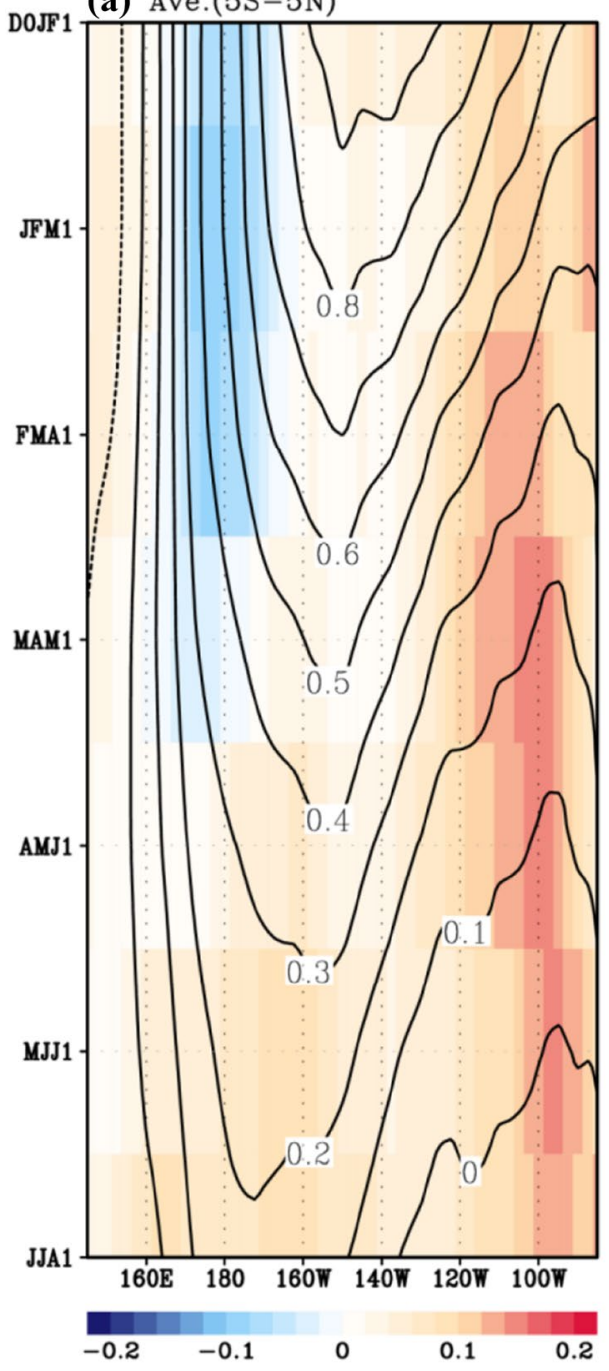

(b) $\mathrm{JFM}(1)$

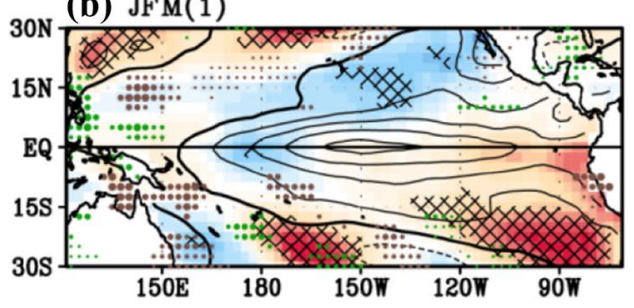

(c) FMA(1)

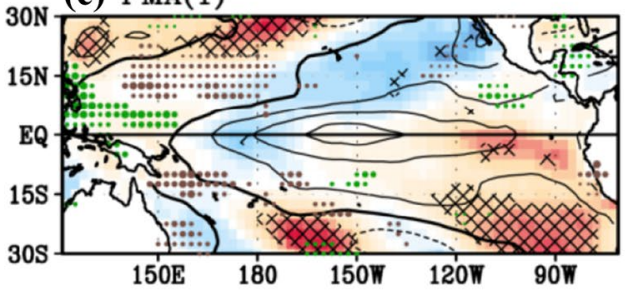

(d) $\operatorname{MAM}(1)$

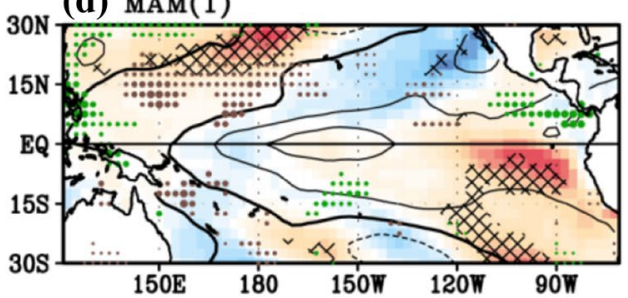

(e) $\operatorname{AMJ}(1)$

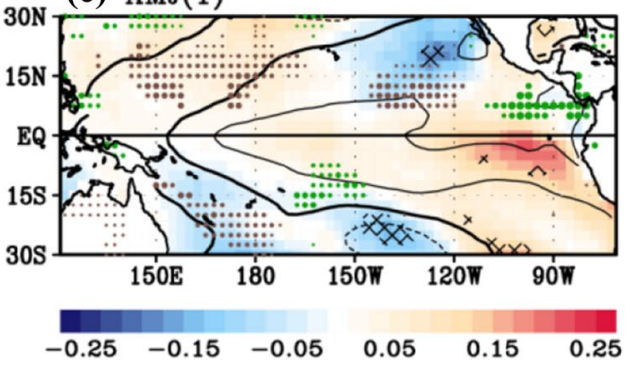

of PNA. For example, there are three anomalous GPH centers in midlatitudes, with the first negative center over the North Pacific, a positive center over the North America, and the second negative center over southeast United States (Fig. 7a, d). Thus, an extratropical teleconnection index is defined as (first positive - first negative)/2, where the second negative center is excluded to focus on the extratropical teleconnection. Then, by regressing the index onto Nino3.4 index $\left(X^{*}(t)\right)$, extratropical-related components $\left(Y(t) \times \operatorname{COV}\left(X^{*}, Y\right) / \operatorname{Var}(Y)\right)$ are obtained. Here, tropicalrelated components $(X(t))$ are defined by subtracting the extratropical-related components from Nino3.4 index.

Next, by conducting a regression analysis using the tropical-related components and extratropical-related components, tropical and extratropical teleconnection related wind anomaly patterns are derived (second and third lows in Fig. 7). From this analysis, it is known that the southwesterly wind anomaly in FMA(1) season is contributed more by the extratropical teleconnections, especially during AMO negative phase (Fig. 7f). But, the contribution from tropical teleconnection appears important as well.

It is interesting to note that the positive center over the North America shifts significantly eastward during the negative AMO phase. Because of such eastward movement of the extratropical teleconnection pattern, anomalous southwesterly winds are stretched more to the eastern TNA during AMO negative phase (Fig. 7). It is argued that such a shift is attributed to the eastward movement of the SST warming pattern associated with El Niño during the AMO negative phase. Due to the eastward shift of the SSTA pattern, anomalous atmospheric heating center shifts also eastward, which leads to the eastward shift of the extratropical teleconnection pattern. The GPH anomaly over the southeast United States exhibits an equivalent barotropic vertical structure. As a result, the mid-level southwesterly wind is in phase with the lower-level southeasterly wind (Fig. 5). 

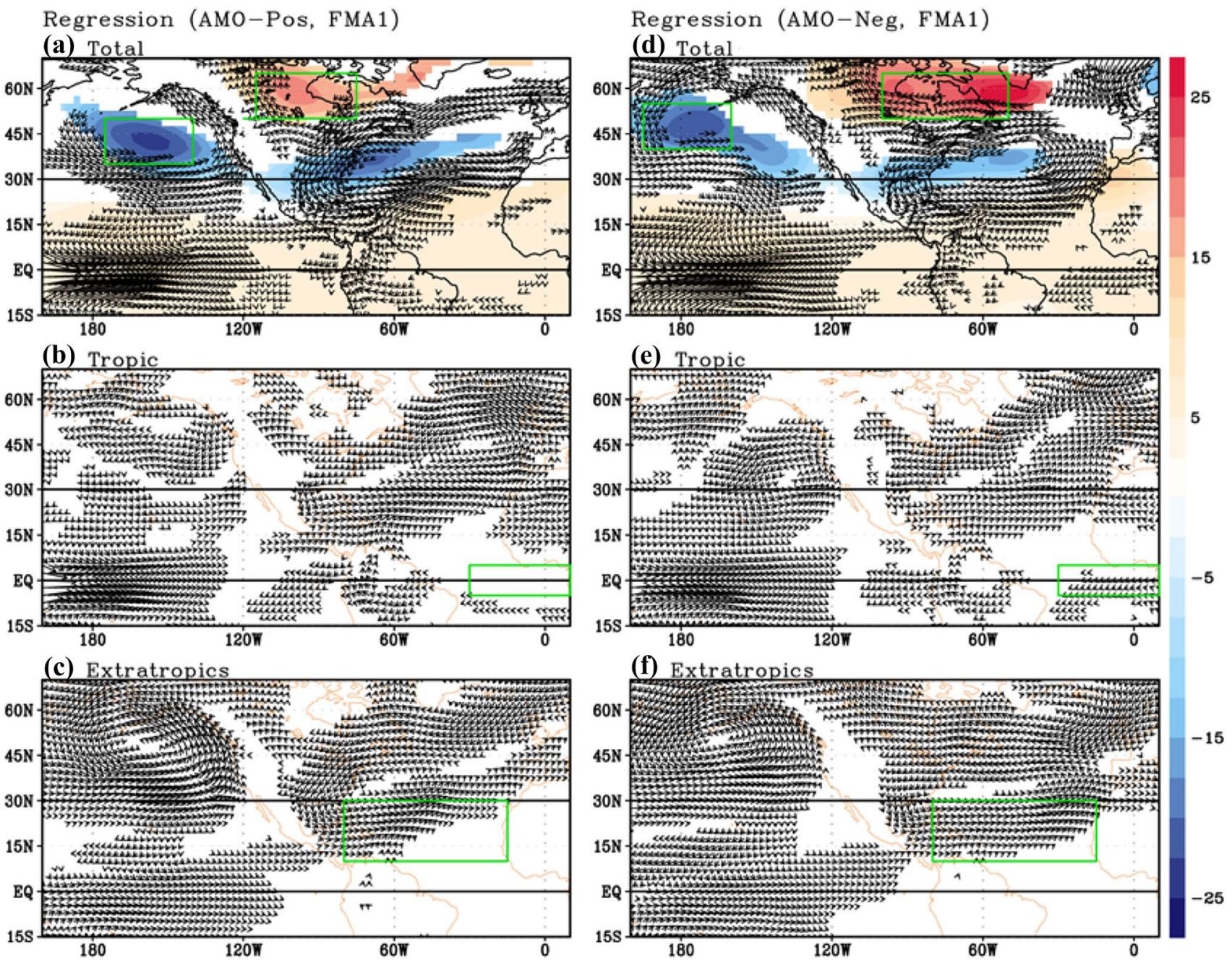

Fig. 7 a Regressed GPH (shading, shading bar is on the right, unit: $\mathrm{m})$ and wind anomalies (vector) at $500 \mathrm{hPa}$ during the the positive AMO against Nino3.4 index, where rectangular boxes correspond to the action centers of the extratropical wave train pattern, where shading and marked wind vectors indicates at $95 \%$ confidence level; b, c indicate regressed wind anomalies against tropical- and extratropi-

\subsubsection{Tropical teleconnection}

To understand how tropical teleconnection can be modulated by the different feature of El Niño, we examine anomalous Walker circulation induced by the El Niño during the positive and negative AMO phases. Left panels in Fig. 8 show anomalous zonal-vertical atmospheric circulation induced by the El Niño during the positive phase of AMO, where bold arrows indicate at $95 \%$ confidence level obtained by two-tailed t-test. It is well known that El Niño induces strong anomalous ascending motion in the central to eastern Pacific $\left(120^{\circ}-180^{\circ} \mathrm{W}\right)$ and descending motion over the Northern Brazil (around $45^{\circ} \mathrm{W}$ ) in $\mathrm{D}(0) \mathrm{JF}(1)$. As time goes by, the anomalous ascending and descending motions get weaker.

cal-related components which are obtained by the partial regression method [refer to manuscript regarding Eq. (1)]; d-f are same to the a-c but during the negative AMO phase. Those exceeding $95 \%$ confidence level are marked in the figure. Rectangular boxes in $\mathbf{b}, \mathbf{c}, \mathbf{e}$, and $\mathbf{f}$ are drawn for comparison of the influence from each component between both AMO phases

In MJJ(1), El Niño induced vertical overturning circulation becomes much weaker.

Right panels in Fig. 8 indicate different zonal-vertical circulation between the negative and positive AMO phases. Here, bold arrows imply above $90 \%$ confidence level obtained by bootstrap method. In FMA(1) (Fig. 8e), anomalous sinking motion appears over the eastern Atlantic near $30^{\circ} \mathrm{E}$, which is connected to low-level easterly wind anomalies. This low-level easterly wind anomalies are also confirmed in Fig. 7e. As both anomalous sinking motion and easterly winds intensify, an anomalous overturning circulation is formed over the Atlantic in MAM(1) (Fig. 8f). In $\operatorname{AMJ}(1)$ and MJJ(1) (Fig. 8g, h), the local overturning circulation is maintained. The anomalous descending motion is 
Lagged-Regression (Zonal Cir. vs. Nino34-Index:D0JF1)

(a) $\operatorname{FMA}(1)$

$$
\text { AMO-Positive }
$$
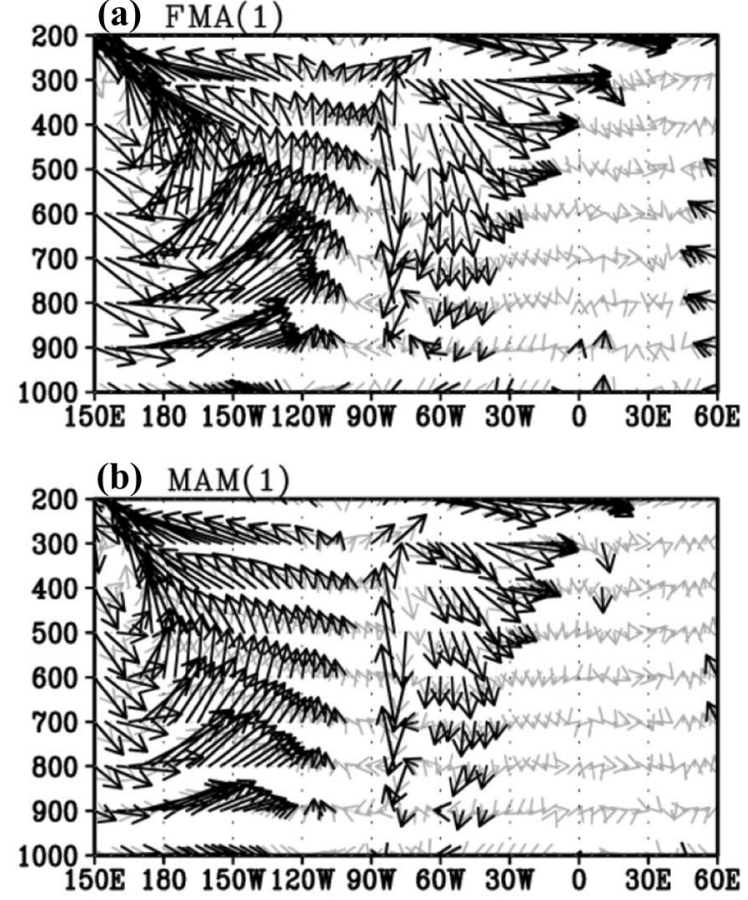

(c) $\operatorname{AMJ}(1)$
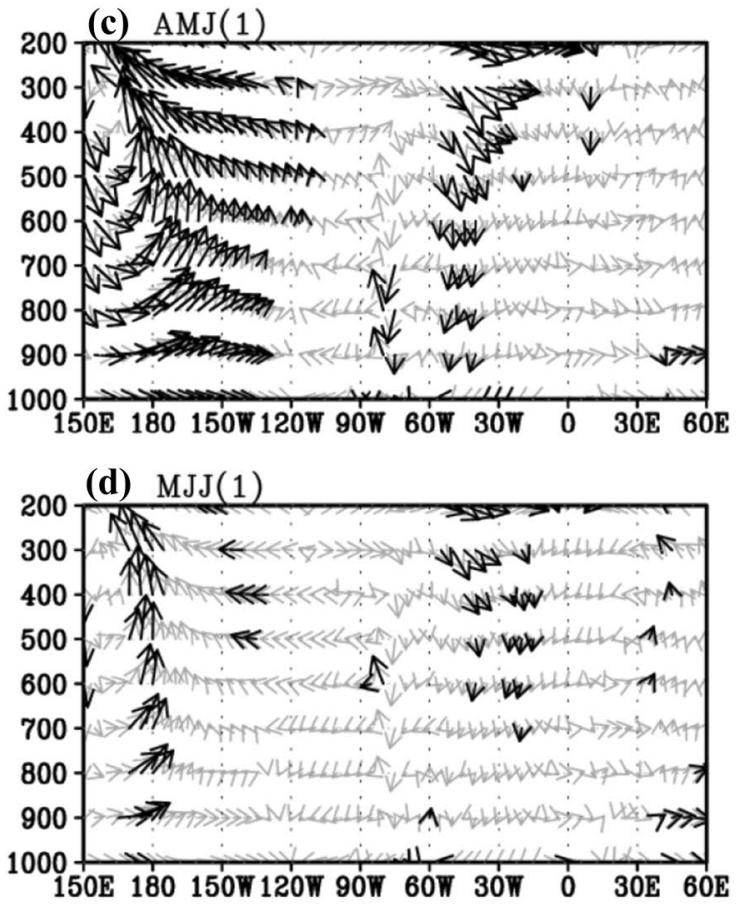

Fig. 8 Lagged correlation coefficients of anomalous zonal circulation $\left(5^{\circ} \mathrm{S}-5^{\circ} \mathrm{N}\right)$ in a FMA, b MAM, c AMJ, and d MJJ seasons against Niño3.4 index for the positive AMO phase. Bold arrows are indicated those above $95 \%$ confidence level by two-tailed t-test. Right panels, (e) FMA(1)

Diff.(Neg-Pos)
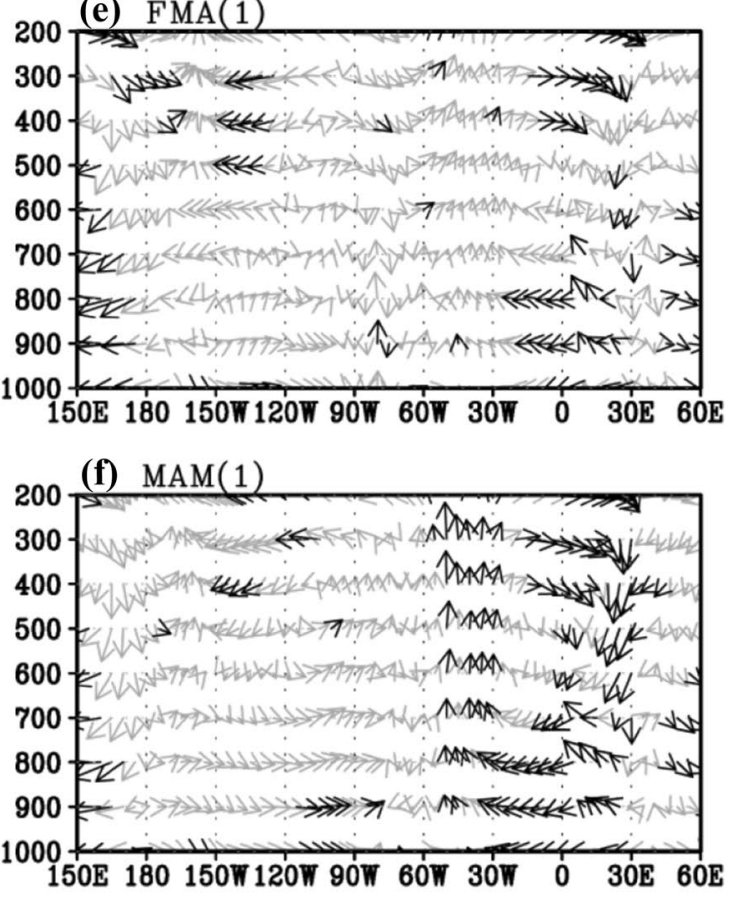

(g) $\operatorname{AMJ}(1)$

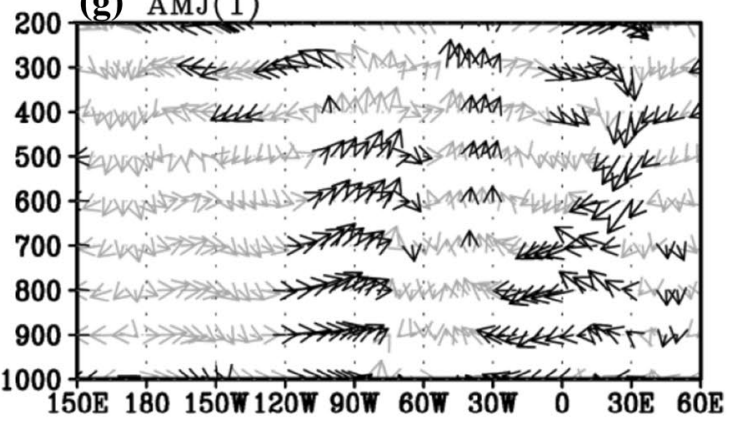

(h) $\operatorname{MJJ}(1)$

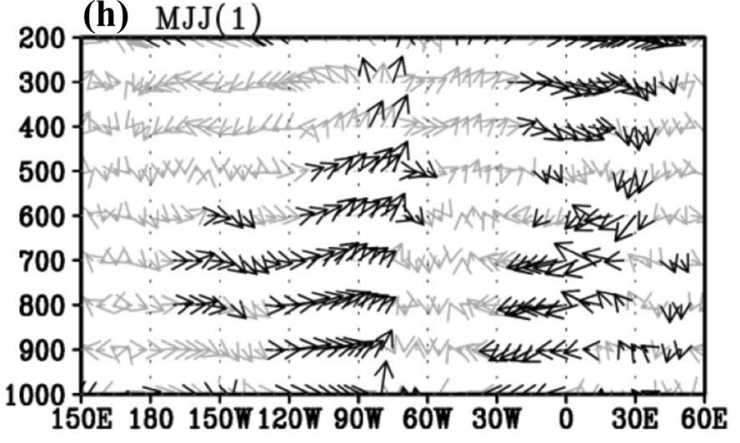

$\mathbf{e}-\mathbf{h}$, show differences in the regressed anomalous zonal circulation between both AMO phases (negative-positive). Bold arrows are indicated those above $90 \%$ confidence level by bootstrap 
consistent with significant negative precipitation anomalies over the far eastern equatorial Atlantic (Fig. 3g-i).

Physically, anomalous sinking motion associated with El Niño induced Kelvin wave response causes negative precipitation anomalies over the eastern equatorial Atlantic (Figs. 8f-h and $3 \mathrm{~h}$ ). Through a Gill-type response to the negative precipitation, southerly/southwesterly wind anomalies occur over its west, which induces SST warming in the TNA. The SST warming and southerly wind anomaly further promote a favorable condition for anomalous positive precipitation in situ. The positive precipitation anomalies over the TNA induce a low-level cyclonic circulation response to its northwest, which further strengthens anomalous southerly/southwesterly winds. This positive air-sea feedback in the TNA during AMO negative phase is critical in the maintenance of TNA-SST warming.

As shown above, anomalous Walker circulation associated to the El Niño penetrates more toward the Atlantic and has a greater impact on precipitation anomaly over the eastern Atlantic during the AMO negative phase, which is related to the intensified and eastward-shifting SST warming and resultant stronger convection over the eastern Pacific (Fig. 6). Since the anomalous Walker circulation is part of the Kelvin wave response, the sinking motion and low-level easterly wind anomaly over the equatorial Atlantic depend on how strongly the Kelvin waves are penetrated toward the Atlantic. Kelvin wave propagation can be visualized by the tropospheric temperature (TT) anomaly (Chiang and Sobel 2002), where TT is defined by the vertically averaged atmospheric temperature anomaly over $850-200 \mathrm{hPa}$. In this light, we checked the time-evolution of TT by correlating it to the Niño3.4 index (Fig. 9). Over the FMA(1) to AMJ(1), one can see that TT is strongly penetrating toward the tropical Atlantic during the AMO negative phase (right panels in Fig. 9), compared to the AMO positive phase (left panels in Fig. 9). Low-level easterly wind anomaly is well superposed to TT expansion along the equatorial Atlantic.

\section{Summary and discussion}

In this study, we examine how different AMO phases modulate the lagged influence of El Niño on the TNA-SST in the following seasons. It is shown that El Niño's influence gets intensified and lasts longer during the negative phase of AMO. The difference is attributed to the fact that the SST warming pattern of El Niño is displaced further to east, and at the same time its intensity lasts longer till late spring during the AMO negative phase. As a result, PNA-like mid-latitude atmospheric teleconnection is intensified and shifted eastward, and anomalous walker circulation can be penetrated more to the eastern equatorial Atlantic in spring. Both the extratropical and tropical teleconnection bring anomalous southwesterly winds in the TNA which makes total wind speed reduced by interacting with northeasterly mean trade winds, leading to the SST warming by latent heat flux reduction in the TNA.

Here, we would like to emphasize the role of the mean ITCZ location over the Atlantic in El Niño induced negative heating anomaly over the TNA. During the AMO negative phase, ITCZ over the Atlantic has a tendency to move equatorward (Fig. 10). Based on the Hadley circulation dynamics (Kang and Lu 2012; Park and An 2014), the equatorward movement of ITCZ brings the equatorward displacement of the subtropical jet. Thus, the equatorward displacement of ITCZ may play a role in promoting the equatorward movement of PNA-like wave train in the Atlantic since the wave train is affected by the subtropical jet. Such equatorward movement of the wave train could help settle the southwesterly wind anomaly in the TNA, contributing to the effective SST warming associated with El Niño.

In addition, considering that ITCZ is known as a region of strong mean convection, such equatorward movement of ITCZ induces a stronger negative heating anomaly response to El Niño near the Equator during the negative phase of AMO. This is why a stronger atmospheric Gill-type response with anomalous subsidence occurred at the equatorial eastern Atlantic during the AMO negative phase. The negative heating further induces a low-level anomalous anticyclone with the pronounced southerly/southwesterly wind anomalies and resultant SST warming over the TNA.

It has been known that the tropical Atlantic is able to influence the Pacific climate on the interannual time scale (Rodríguez-Fonseca et al. 2009; Ham et al. 2013; Yu et al. 2016; Li et al. 2017; Park et al. 2018a, b, c). Such an influence of the Atlantic on the Pacific can be inferred in Fig. 2a, where negative axis indicates TNA influence on Niño3.4. In the figure, one may see the decadal modulation of Atlantic influence on Pacific as well. The period of weaker Pacific influence on the Atlantic matches well with the AMO positive phase, and vice versa. Especially, in recent decades Atlantic Warm Pool (a.k.a. Western Hemisphere Warm Pool) in the TNA is able to lead El Niño with a lag beyond 1 year (Park et al. 2018b, c), as shown in Fig. 2a where the lagged correlation coefficient is significantly risen up to -0.46 . It is interesting to further investigate such a decadal modulation of interannual relationship between Pacific and Atlantic according to the AMO phase (Svendsen et al. 2014; MartínRey et al. 2014).

An interesting feature during the negative AMO phase is strong easterly wind anomalies along the eastern equatorial Atlantic over the spring to early summer seasons (Fig. 8e-h). The easterly anomalies lead to a SST cooling in the eastern equatorial Atlantic, through inducing upwelling, as confirmed in Fig. 3i. Such a SST pattern resembles an Atlantic Niño (Chang et al. 2006a). Therefore, the AMO negative 
Correlation (TT vs. Nino34:D0JF1, AMO:Pos. \& AMo:Neg., 95\%)

(a) $\operatorname{JFM}(1)$

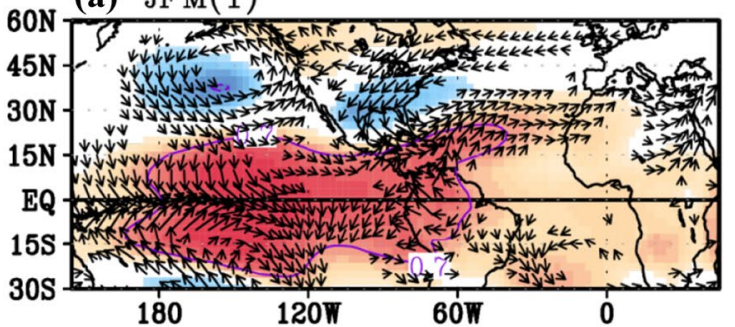

(b) FMA(1)

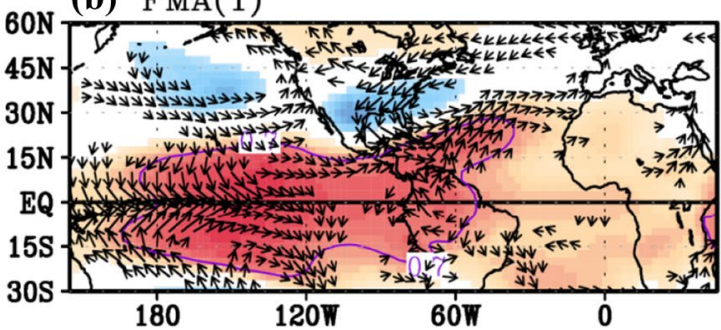

(c) $\operatorname{MAM}(1)$
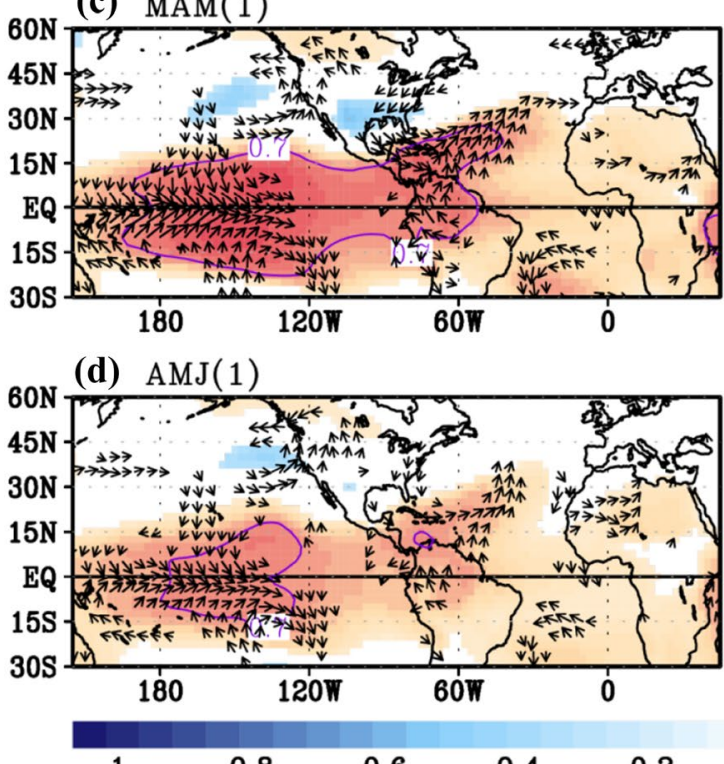

Fig. 9 a-d Show lagged correlation maps of tropospheric temperature (TT, shading) and lower-level wind anomaly (vectors) from FMA to AMJ seasons during the positive AMO phase, where contour indi-

phase may strengthen the effect of El Niño on SST variability near the Atlantic Niño region in summer. Since it is reported that Atlantic Niño efficiently induces La Niña only during the AMO negative phase (Martín-Rey et al. 2014), it is needed to investigated that the AMO phase plays a critical role in on-and-off interaction between Pacific and Atlantic Niños in near future.

One question related to the AMO modulation on the El Niño-TNA relationship is whether or not such a modulation can be simulated by the state-of-the art climate models. In order to answer this question, we conducted a

(e) $\operatorname{JFM}(1)$

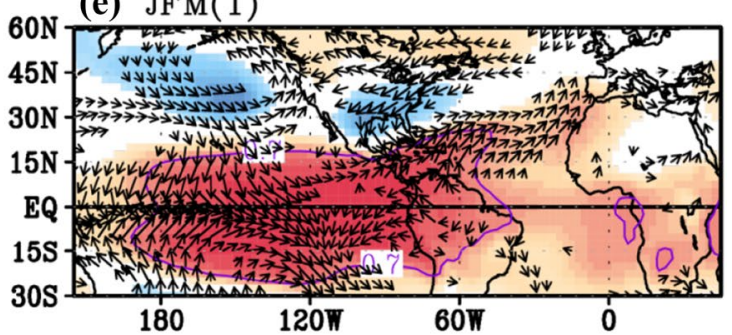

(f) $\mathrm{FMA}(1)$

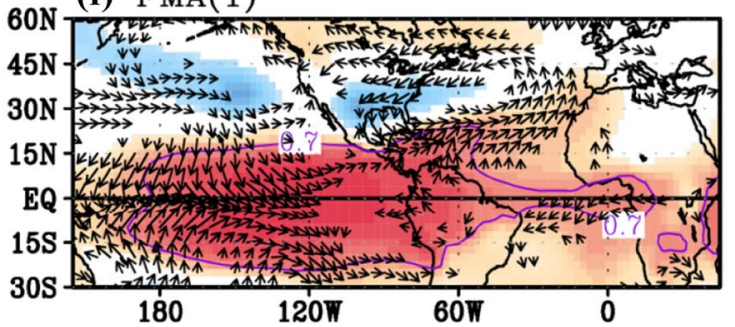

(g) $\operatorname{MAM}(1)$
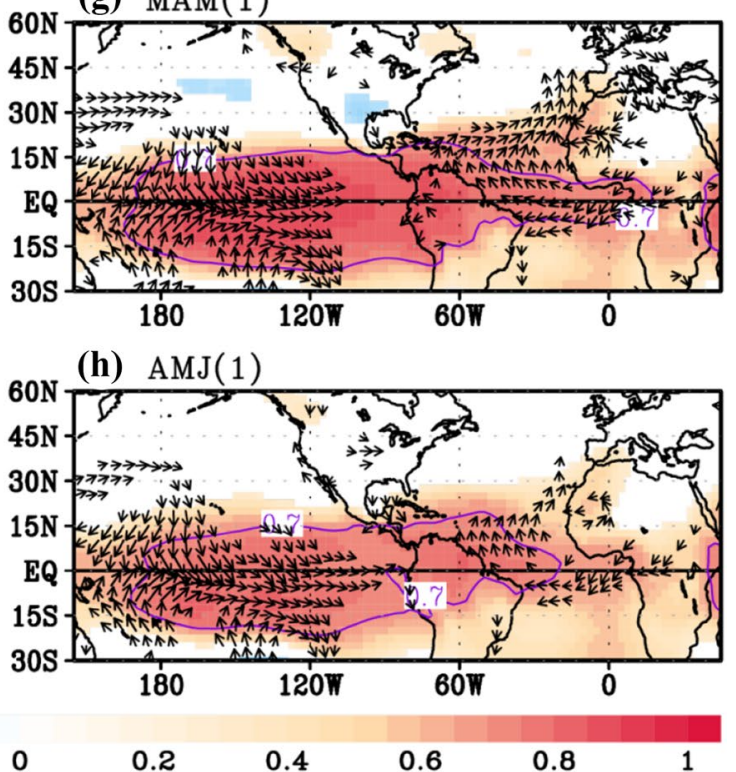

cate a 0.7 correlation coefficient line of TT; $\mathbf{e}-\mathbf{h}$ are same to the $\mathbf{a}-\mathbf{d}$ but during the negative AMO phase

similar analysis using the 1000-year preindustrial simulations of CCSM4 and GFDL-CM3 participated in the CMIP5. While models are able to reasonably simulate the influence of El Niño on TNA-SST in spring, the interdecadal modulation of the El Niño-TNA relationship by AMO is not well reproduced. This is probably because El Niño intensity and structure are not well simulated, and so are simulated Atlantic mean climatology and AMO. More careful investigation regarding the mutual influence between Pacific and Atlantic in the climate models is needed. 


\section{Climatology \& Diff. (Pr, 90\%)}

(a) JFM

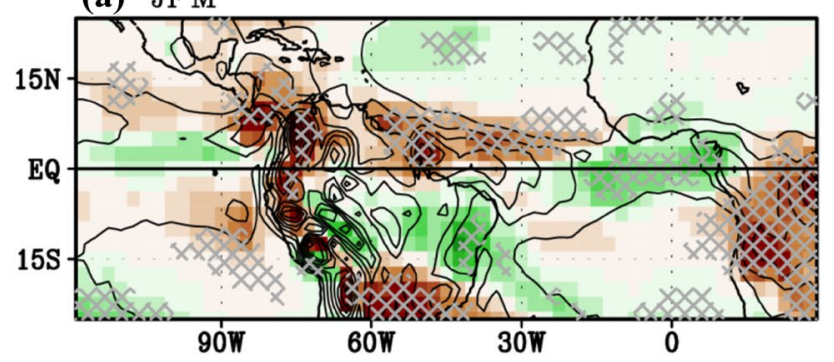

(b) MAM

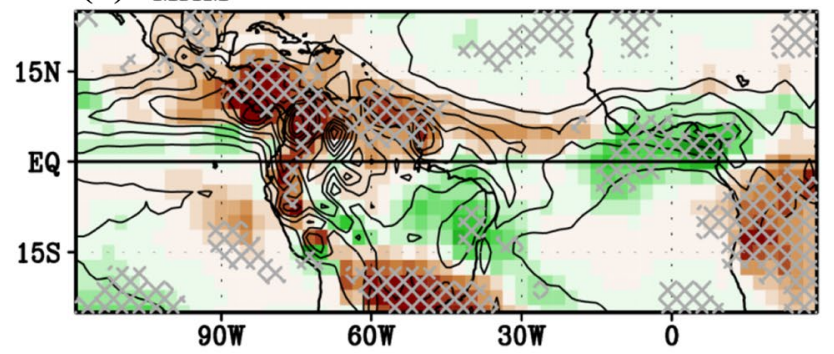

(c) $\mathrm{MJJ}$

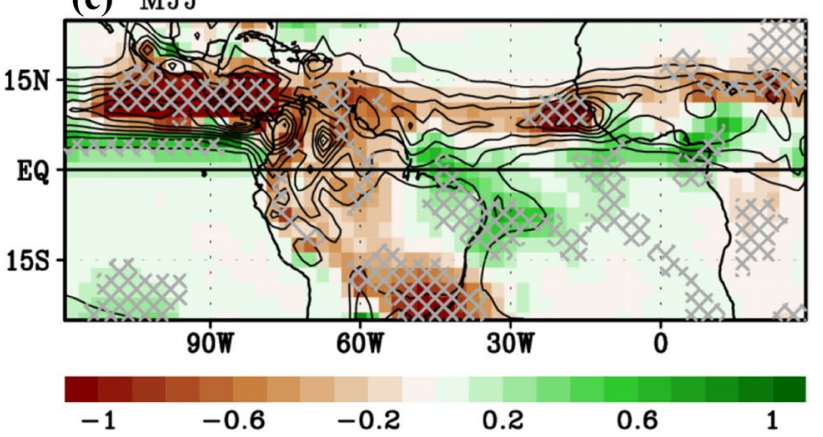

Fig. 10 a Climatology of precipitation (interval is $2.5 \mathrm{~mm} /$ day) during the positive AMO phase and its difference (negative-positive, shading, hatching indicates $90 \%$ confidence level by bootstrap method) between both AMO phases are illustrated in JFM; b, $\mathbf{c}$ are same to a but in MAM and MJJ seasons, respectively

It has been argued that recent Atlantic warming trend plays a role in causing a La Niña-like mean state in the Pacific via easterly wind anomaly (England et al. 2014; McGregor et al. 2014; Yu et al. 2015; Li et al. 2016). The argument above seems consistent with the current result that increased Atlantic interannual influence on the El Niño is found during positive phase of AMO. This study reveals the different El Niño warming pattern according to the AMO phase. We showed that AMO negative (positive) phase favors the occurrence of eastern (central) Pacific-type El Niño, and that the El Niño tends to persist throughout late spring during AMO negative phase. Previous studies indicated that El Niño flavors are also modulated by PDO or IPO (Power et al. 1999; Chung and Li 2013; Xiang et al. 2013). It should be interesting to further investigate the relative role of AMO and IPO in modulating the EP and CP El Niños.
Acknowledgements This work was supported by NSFC Project 41630423, NSF Grant AGS-1565653, NOAA grant NA18OAR4310298, NSFC Project 41475084/41875069, and JAMSTEC JIJI Theme 1 project. This is SOEST Contribution Number 10457 and IPRC Contribution Number 1345.

Open Access This article is distributed under the terms of the Creative Commons Attribution 4.0 International License (http://creativeco mmons.org/licenses/by/4.0/), which permits unrestricted use, distribution, and reproduction in any medium, provided you give appropriate credit to the original author(s) and the source, provide a link to the Creative Commons license, and indicate if changes were made.

\section{References}

An SI, Wang B (2005) The forced and intrinsic low-frequency models in the North Pacific. J Clim 18:876-885

Barnston AG, Livezey RE (1987) Classification, seasonality and persistence of low-frequency atmospheric circulation patterns. Mon Weather Rev 115:1083-1126

Bond N, Overland J, Spillane M, Stabeno P (2003) Recent shifts in the state of the North Pacific. Geophys Res Lett 30:2183. https://doi. org/10.1029/2003GL018597

Cassou C, Terray L (2001) Oceanic forcing of the wintertime lowfrequency atmospheric variability in the North Atlantic European sector: a study with the ARPEGE model. J Clim 14:4266-4291. https://doi.org/10.1175/1520-0442(2001)014<4266:Ofotw $1>2.0 . \mathrm{Co} ; 2$

Cassou C, Terray L, Hurrell JW, Deser C (2004) North Atlantic winter climate regimes: spatial asymmetry, stationarity with time, and oceanic forcing. J Clim 17:1055-1068. https://doi. org/10.1175/1520-0442(2004)017<1055:Nawcrs > 2.0.Co;2

Chang EK (2006) An idealized nonlinear model of the Northern Hemisphere winter storm tracks. J Atmos Sci 63:1818-1839

Chang P, Saravanan R, Ji L, Hegerl GC (2000) The effect of local sea surface temperatures on atmospheric circulation over the tropical Atlantic sector. J Clim 13:2195-2216. https://doi. org/10.1175/1520-0442(2000)013<2195:Teolss $>2.0$. Co;2

Chang P, Fang Y, Saravanan R, Ji L, Seidel H (2006) The cause of the fragile relationship between the Pacific El Niño and the Atlantic Niño. Nature 443:324. https://doi.org/10.1038/nature05053

Chen S, Wu R, Chen W (2015) The changing relationship between interannual variations of the North Atlantic oscillation and Northern Tropical Atlantic SST. J Clim 28:485-504

Chiang JCH, Lintner BR (2005) Mechanisms of remote tropical surface warming during El Niño. J Clim 18:4130-4149. https://doi. org/10.1175/jcli3529.1

Chiang JCH, Sobel AH (2002) Tropical tropospheric temperature variations caused by ENSO and their influence on the remote tropical climate. J Clim 15:2616-2631. https://doi.org/10.1175/15200442(2002)015<2616:Tttvcb > 2.0.Co;2

Chung P-H, Li T (2013) Interdecadal relationship between the mean state and El Niño types. J Clim 26:361-379

Compo GP et al (2011) The twentieth century reanalysis project. Q J R Meteor Soc 137:1-28

Di Lorenzo E et al (2008) North Pacific Gyre oscillation links ocean climate and ecosystem change. Geophys Res Lett. https://doi. org/10.1029/2007GL032838

Enfield DB, Mayer DA (1997) Tropical Atlantic sea surface temperature variability and its relation to El Niño-Southern Oscillation. J Geophys Res Oceans 102:929-945 
England MH et al (2014) Recent intensification of wind-driven circulation in the Pacific and the ongoing warming hiatus. Nat Clim Change 4:222-227

Folland CK, Palmer TN, Parker DE (1986) Sahel rainfall and worldwide sea temperatures, 1901-85. Nature 320:602

García-Serrano J, Cassou C, Douville H, Giannini A, Doblas-Reyes FJ (2017) Revisiting the ENSO teleconnection to the tropical North Atlantic. J Clim 30:6945-6957

Giannini A, Cane MA, Kushnir Y (2001) Interdecadal changes in the ENSO teleconnection to the Caribbean region and the North Atlantic oscillation. J Clim 14:2867-2879

Giannini A, Saravanan R, Chang P (2004) The preconditioning role of tropical Atlantic variability in the development of the ENSO teleconnection: implications for the prediction of Nordeste rainfall. Clim Dyn 22:839-855. https://doi.org/10.1007/s0038 2-004-0420-2

Goldenberg SB, Landsea CW, Mestas-Nuñez AM, Gray WM (2001) The recent increase in Atlantic hurricane activity: causes and implications. Science 293:474-479

Ham Y-G, Kug J-S, Park J-Y, Jin F-F (2013) Sea surface temperature in the north tropical Atlantic as a trigger for El Niño/Southern Oscillation events. Nat Geosci 6:112-116

Henley BJ, Gergis J, Karoly DJ, Power S, Kennedy J, Folland CK (2015) A tripole index for the interdecadal Pacific oscillation. Clim Dyn 45:3077-3090. https://doi.org/10.1007/s0038 2-015-2525-1

Horel JD, Wallace JM (1981) Planetary-scale atmospheric phenomena associated with the Southern Oscillation. Mon Weather Rev 109:813-829

Hoskins BJ, Karoly DJ (1981) The steady linear response of a spherical atmosphere to thermal and orographic forcing. J Atmos Sci 38:1179-1196

Huang B, Shukla J (2005) Ocean-atmosphere interactions in the tropical and subtropical Atlantic Ocean. J Clim 18:1652-1672. https:// doi.org/10.1175/jcli3368.1

Hurrell JW, Kushnir Y, Ottersen G, Visbeck M (2013) An overview of the North Atlantic oscillation. In: Hurrell JW, Kushnir Y, Ottersen G, Visbeck M (eds) The North Atlantic oscillation: climatic significance and environmental impact. Wiley, Hoboken, United States. https://doi.org/10.1029/134GM01

Kang SM, Lu J (2012) Expansion of the Hadley cell under global warming: winter versus summer. J Clim 25:8387-8393. https:// doi.org/10.1175/jcli-d-12-00323.1

Klein SA, Soden BJ, Lau N-C (1999) Remote sea surface temperature variations during ENSO: evidence for a tropical atmospheric bridge. J Clim 12:917-932

Kushnir Y, Seager R, Ting M, Naik N, Nakamura J (2010) Mechanisms of tropical Atlantic SST influence on North American precipitation variability. J Clim 23:5610-5628

Lee SK, Enfield DB, Wang C (2008) Why do some El Niños have no impact on tropical North Atlantic SST? Geophys Res Lett. https ://doi.org/10.1029/2008GL034734

Lee S-K, Wang C, Mapes BE (2009) A simple atmospheric model of the local and teleconnection responses to tropical heating anomalies. J Clim 22:272-284. https://doi.org/10.1175/2008jcli2303.1

Li X, Xie S-P, Gille ST, Yoo C (2016) Atlantic-induced pan-tropical climate change over the past three decades. Nat Clim Change 6:275-279. https://doi.org/10.1038/nclimate2840

Li T, Wang B, Wu B, Zhou T, Chang C-P, Zhang R (2017) Theories on formation of an anomalous anticyclone in western North Pacific during El Niño. Rev J Meteor Res 31:987-1006. https:// doi.org/10.1007/s13351-017-7147-6

Mantua NJ, Hare SR, Zhang Y, Wallace JM, Francis RC (1997) A Pacific interdecadal climate oscillation with impacts on salmon production. Bull Am Meteor Soc 78:1069-1079
Marshall J, Johnson H, Goodman J (2001) A Study of the interaction of the North Atlantic Oscillation with ocean circulation. J Clim 14:1399-1421. https://doi. org/10.1175/1520-0442(2001)014<1399:Asotio>2.0.Co;2

Martín-Rey M, Rodríguez-Fonseca B, Polo I, Kucharski F (2014) On the Atlantic-Pacific Niños connection: a multidecadal modulated mode. Clim Dyn 43:3163-3178. https://doi.org/10.1007/s0038 2-014-2305-3

McGregor S, Timmermann A, Stuecker MF, England MH, Merrifield M, Jin F-F, Chikamoto Y (2014) Recent Walker circulation strengthening and Pacific cooling amplified by Atlantic warming. Nat Clim Change 4:888-892

Okumura Y, Xie SP, Numaguti A, Tanimoto Y (2001) Tropical Atlantic air-sea interaction and its influence on the NAO. Geophys Res Lett 28:1507-1510

Park JH, An SI (2014) Southward displacement of the upper atmosphere zonal jet in the eastern north Pacific due to global warming. Geophys Res Lett 41:7861-7867

Park JH, Kug JS, An SI, Li T (2018a) Role of the Western Hemisphere warm pool in climate variability over the western North Pacific. Clim Dyn (under revision)

Park JH, Kug JS, Li T, Behera SK (2018b) Predicting El Niño beyond 1-year lead: effect of the Western Hemisphere warm pool. Sci Rep (accepted)

Park JH, Li T, Yeh SW, Kim H (2018c) Effect of recent Atlantic warming in strengthening Atlantic-Pacific teleconnection on interannual timescale via enhanced connection with the Pacific meridional mode. Clim Dyn (under revision)

Power S, Casey T, Folland C, Colman A, Mehta V (1999) Inter-decadal modulation of the impact of ENSO on Australia. Clim Dyn 15:319-324

Reynolds RW, Rayner NA, Smith TM, Stokes DC, Wang W (2002) An improved in situ and satellite SST analysis for climate. J Clim 15:1609-1625

Rodríguez-Fonseca B, Polo I, García-Serrano J, Losada T, Mohino E, Mechoso CR, Kucharski F (2009) Are Atlantic Niños enhancing Pacific ENSO events in recent decades? Geophys Res Lett 36:L20705. https://doi.org/10.1029/2009GL040048

Saunders MA, Lea AS (2008) Large contribution of sea surface warming to recent increase in Atlantic hurricane activity. Nature 451:557

Svendsen L, Kvamst $\varnothing$ NG, Keenlyside N (2014) Weakening AMOC connects equatorial Atlantic and Pacific interannual variability. Clim Dyn 43:2931-2941. https://doi.org/10.1007/s0038 2-013-1904-8

Tourre YM, Rajagopalan B, Kushnir Y (1999) Dominant patterns of climate variability in the Atlantic Ocean during the last 136 years. J Clim 12:2285-2299. https://doi. org/10.1175/1520-0442(1999)012<2285:Dpocvi $>2.0$. Co;2

Trenberth KE, Shea DJ (2006) Atlantic hurricanes and natural variability in 2005. Geophys Res Lett 33:L12704. https://doi. org/10.1029/2006GL026894

Uvo CB, Repelli CA, Zebiak SE, Kushnir Y (1998) The relationships between tropical Pacific and Atlantic SST and northeast Brazil monthly precipitation. J Clim 11:551-562

van Oldenborgh GJ et al (2009) Western Europe is warming much faster than expected. Clim Past 5:1-12

Wallace JM, Gutzler DS (1981) Teleconnections in the geopotential height field during the Northern Hemisphere winter. Mon Weather Rev 109:784-812

Wang C (2004) ENSO, Atlantic climate variability, and the Walker and Hadley circulations. In: The Hadley circulation: present, past and future. Springer, Berlin, pp 173-202

Wang C, Lee S-K, Enfield DB (2008) Climate response to anomalously large and small Atlantic warm pools during the summer. J Clim 21:2437-2450 
Xiang B, Wang B, Li T (2013) A new paradigm for the predominance of standing central Pacific warming after the late 1990s. Clim Dyn 41:327-340

Yu J-Y, Kao P-k, Paek H, Hsu H-H, Hung C-w, Lu M-M, An S-I (2015) Linking emergence of the central Pacific El Niño to the Atlantic multidecadal oscillation. J Clim 28:651-662
Yu J, Li T, Tan Z, Zhu Z (2016) Effects of tropical North Atlantic SST on tropical cyclone genesis in the western North Pacific. Clim Dyn 46:865-877 